ARTICLE

https://doi.org/10.1038/s41467-019-12781-7

\title{
Extracellular pyridine nucleotides trigger plant systemic immunity through a lectin receptor kinase/BAK1 complex
}

\author{
Chenggang Wang (10) ${ }^{1,6}$, Xiaoen Huang (1) ${ }^{2,5,6}$, Qi Li (i) ${ }^{1}$, Yanping Zhang (1) ${ }^{3}$, Jian-Liang Li (i) ${ }^{4}$ \& \\ Zhonglin Mou (1) ${ }^{1 \star}$
}

Systemic acquired resistance (SAR) is a long-lasting broad-spectrum plant immunity induced by mobile signals produced in the local leaves where the initial infection occurs. Although multiple structurally unrelated signals have been proposed, the mechanisms responsible for perception of these signals in the systemic leaves are unknown. Here, we show that exogenously applied nicotinamide adenine dinucleotide $\left(\mathrm{NAD}^{+}\right)$moves systemically and induces systemic immunity. We demonstrate that the lectin receptor kinase (LecRK), LecRK-VI.2, is a potential receptor for extracellular $\mathrm{NAD}^{+}\left(\mathrm{eNAD}^{+}\right)$and $\mathrm{NAD}^{+}$phosphate $\left(\mathrm{eNADP}{ }^{+}\right)$and plays a central role in biological induction of SAR. LecRK-VI.2 constitutively associates with BRASSINOSTEROID INSENSITIVE1-ASSOCIATED KINASE1 (BAK1) in vivo. Furthermore, BAK1 and its homolog BAK1-LIKE1 are required for eNAD(P)+ signaling and SAR, and the kinase activities of LecR-VI.2 and BAK1 are indispensable to their function in SAR. Our results indicate that $\mathrm{eNAD}^{+}$is a putative mobile signal, which triggers SAR through its receptor complex LecRK-VI.2/BAK1 in Arabidopsis thaliana.

\footnotetext{
${ }^{1}$ Department of Microbiology and Cell Science, University of Florida, Gainesville, FL 32611, USA. ${ }^{2}$ Department of Plant Pathology, University of Florida, Gainesville, FL 32611, USA. ${ }^{3}$ Interdisciplinary Center for Biotechnology Research, University of Florida, Gainesville, FL 32610, USA. ${ }^{4}$ National Institute of Environmental Health Sciences, NIH, Research Triangle Park, NC 27709, USA. ${ }^{5}$ Present address: Citrus Research and Education Center, University of Florida, 700 Experiment Station Road, Lake Alfred, FL 33850, USA. ${ }^{6}$ These authors contributed equally: Chenggang Wang, Xiaoen Huang. ${ }^{\star}$ email: zhlmou@ufl.edu
} 
ll eukaryotes possess a sophisticated immune system to defend against microbial pathogens. Whereas animals employ both innate and adaptive immunities, plants lack adaptive immunity and strictly rely on innate immunity. Every plant cell is capable of using the so-called two-tiered innate immune system to detect potential microbial pathogens and mount immune responses ${ }^{1}$. In the local leaves where the initial infection occurs, plant cells utilize pattern recognition receptors (PRRs) to sense conserved features on/in the invading microbes, which are named pathogen-associated molecular patterns (PAMPs), and activate PAMP-triggered immunity (PTI). Successful pathogens employ effectors to dampen PAMP signaling. Resistant plants in turn exploit resistance proteins to detect the presence of pathogen effectors, inducing effector-triggered immunity. These plant-pathogen battles often cause injuries to the plant cells, resulting in release of host-derived damage-associated molecular patterns (DAMPs) that further potentiate immunity through $\mathrm{PRRs}^{2}$.

Pathogen perturbation in the local leaves induces production of mobile signals that are transported to the uninfected parts (the systemic leaves) of the plant, leading to the activation of a longlasting form of immunity known as systemic acquired resistance (SAR) that confers resistance to subsequent infections by a broad spectrum of pathogens ${ }^{3}$. A group of structurally unrelated molecules have been proposed as SAR mobile signals, which include the lipid transfer protein Defective in Induced Resistancel (DIR1) ${ }^{4}$, salicylic acid (SA) and its derivative methyl $\mathrm{SA}^{5-7}$, dehydroabietinal $^{8}$, azelaic acid (AzA $)^{9}$, glycerol-3-phosphate $(\mathrm{G} 3 \mathrm{P})^{10}$, pipecolic acid (Pip) and its derivative $N$-hydroxy-Pip (NHP) ${ }^{11-13}$, and monoterpenes ${ }^{14}$. In addition, nitric oxide (NO) and reactive oxygen species (ROS) have been implicated in the SAR signaling amplification loop ${ }^{15,16}$. It has been suggested that NO, ROS, AzA, and G3P function in a pathway in parallel with the SA pathway in SAR signaling and that Pip acts upstream of the NO-ROS-AzAG3P branch ${ }^{7,16}$. However, how these SAR signals are perceived in the systemic leaves remains unclear.

Nicotinamide adenine dinucleotide $\left(\mathrm{NAD}^{+}\right)$and $\mathrm{NAD}^{+}$ phosphate $\left(\mathrm{NADP}^{+}\right)$are universal electron carriers functioning in both metabolic reactions and intracellular signaling ${ }^{17}$. Accumulating evidence has indicated that cellular $\mathrm{NAD}(\mathrm{P})^{+}$can also be released into the extracellular space to stimulate outside-in signaling ${ }^{18}$. In plants, extracellular $\mathrm{NAD}(\mathrm{P})^{+}\left[\mathrm{eNAD}(\mathrm{P})^{+}\right]$elicits transcriptional and metabolic changes similar to those induced by pathogen infection, and pathogen infection leads to leakage of $\mathrm{NAD}(\mathrm{P})^{+}$into the extracellular fluid at concentrations sufficient for immune activation ${ }^{19,20}$. Furthermore, transgenic expression of the human $\mathrm{NAD}(\mathrm{P})^{+}$-hydrolyzing ectoenzyme CD38 in Arabidopsis thaliana (Arabidopsis) partially compromises biological induction of $\mathrm{SAR}^{21}$. These results suggest that $\mathrm{eNAD}(\mathrm{P})^{+}$may be an SAR signal molecule. Recently, we identified the Arabidopsis legume-like lectin receptor kinase (LecRK), LecRK-I.8, as a potential $\mathrm{eNAD}^{+}$receptor $^{22}$. However, LecRK-I.8 does not bind $\mathrm{NADP}^{+}$and mutations in LecRK-I.8 have no effect on biological induction of $\mathrm{SAR}^{22}$. Thus, the identity of the $\mathrm{NADP}^{+}$-binding receptor and whether $\mathrm{eNAD}(\mathrm{P})^{+}$is an SAR signal molecule remain to be uncovered.

In this study, we show that $\mathrm{eNAD}^{+}$is a putative SAR mobile signal and demonstrate that the eNAD $(\mathrm{P})^{+}$receptor complex LecRK-VI.2/BAK1 (Brassinosteroid insensitive1-Associated Kinase1) is a key signaling component of SAR in Arabidopsis.

\section{Results}

Exogenous $\mathrm{NAD}^{+}$and/or its derivative(s) move systemically. We have shown that exogenous application of $\mathrm{NAD}(\mathrm{P})^{+}$induces immune responses and that depletion of $\operatorname{eNAD}(\mathrm{P})^{+}$by transgenic expression of the human $\mathrm{NAD}(\mathrm{P})^{+}$-hydrolyzing ectoenzyme CD38 partially compromises biological induction of SAR in Arabidopsis ${ }^{19,21}$. These results strongly suggest that $\operatorname{eNAD}(\mathrm{P})^{+}$ may be an SAR signal molecule. However, when infiltrated into lower leaves of Arabidopsis plants, only $\mathrm{NAD}^{+}$at a concentration $(5 \mathrm{~mm})$ higher than physiological levels $(\sim 0.4 \mathrm{~mm})$ was able to induce a partial and significant resistance (intermediate resistance) in the systemic leaves ${ }^{21}$. We reasoned that, during pathogen infection, $\mathrm{NAD}(\mathrm{P})^{+}$might continuously leak into the extracellular space to trigger SAR. To test this hypothesis, we measured the virulent bacterial pathogen Pseudomonas syringae pv. maculicola ES4326 (Psm)-induced NAD(P) (both oxidized and reduced forms) leakage from leaf disks floating on water. As shown in Fig. $1 \mathrm{a}, \mathrm{b}$, the amounts of $\mathrm{NAD}(\mathrm{P})$ in the water surrounding the Psm-infiltrated leaf disks were significantly higher than those surrounding the mock $\left(10 \mathrm{mM} \mathrm{MgCl}_{2}\right)$-infiltrated leaf disks in the first $36 \mathrm{~h}$. To test whether NAD $(\mathrm{P})$ could leak out of intact leaves, detached leaves were submerged in water with the petioles above the water surface. As shown in Supplementary Fig. 1a, b, NAD $(\mathrm{P})$ levels in the water covering Psm-infiltrated leaves increased significantly at 36 and 48 hour. The slower kinetics of $\mathrm{NAD}(\mathrm{P})$ leakage from intact leaves than from leaf disks may be attributed to the process of diffusing out of the apoplast. Nevertheless, these results indicate that significant amounts of $\mathrm{NAD}(\mathrm{P})$ leaked into the extracellular space after Psm infection.

To mimic the eNAD $(\mathrm{P})^{+}$dynamics during pathogen infection, we infiltrated three lower leaves on each Arabidopsis plant with $0.4 \mathrm{mM} \mathrm{NAD}^{+}$or $0.8 \mathrm{~mm} \mathrm{NADP}^{+}$every 12 hours for a total of four times. Approximately 5 hours after the last infiltration, the systemic leaves were collected for analysis of the induction of Pathogenesis-Related gene1 (PR1), a marker gene of SAR ${ }^{23}$. To test $\mathrm{NAD}(\mathrm{P})^{+}$-induced systemic resistance, the systemic leaves were challenge-inoculated with Psm and the in planta bacterial growth was determined 3 days later. Meanwhile, Psm-triggered biological induction of SAR was used as the positive control. To this end, three lower leaves on each plant were infiltrated with Psm. Two days later, the systemic leaves were either collected for PR1 analysis or challenge-inoculated with Psm for resistance test. As shown in Fig. 1c, d, treatment of lower leaves with $\mathrm{NAD}(\mathrm{P})^{+}$ significantly induced expression of $P R 1$ and resistance to Psm in the systemic leaves, though the induction levels were significantly lower than those triggered by Psm, which is consistent with the notion that multiple signal molecules are involved in SAR activation $^{24}$. Taken together, these results suggest that $\operatorname{eNAD}(\mathrm{P})^{+}$ may function as an SAR signal molecule in Arabidopsis.

$\mathrm{NAD}(\mathrm{P})^{+}$may act in the infiltrated (local) leaves or be transported to the systemic leaves to trigger resistance. To test whether $\operatorname{eNAD}(\mathrm{P})^{+}$-triggered systemic resistance is associated with translocation of eNAD $(\mathrm{P})^{+}$from local to systemic leaves, an $\mathrm{NAD}^{+}$solution ( $1 \mathrm{~mm}$ unlabeled $\mathrm{NAD}^{+}$plus $6.25 \mathrm{~nm}^{32} \mathrm{P}_{-\mathrm{NAD}}{ }^{+}$) was infiltrated into lower leaves on Arabidopsis and Nicotiana benthamiana plants (Fig. 1e, f). Twenty-four hours later, the systemic leaves were collected for autoradiographic detection of ${ }^{32} \mathrm{P}$. As shown in Fig. 1e, f, infiltration of ${ }^{32} \mathrm{P}-\mathrm{NAD}^{+}$resulted in movement of the radioactivity into the systemic leaves in both Arabidopsis and N. benthamiana. To define the portion of radioactivity that moves systemically, Arabidopsis leaves were infiltrated with $6.25 \mathrm{~nm}^{32} \mathrm{P}_{-\mathrm{NAD}^{+}}$(without unlabeled $\mathrm{NAD}^{+}$) and the radioactivity in the local and systemic leaves was quantified. As shown in Supplementary Fig. 2a, $\sim 10.8 \%$ and $6.1 \%$ of the radioactivity moved into the systemic leaves in the wild type and the $35 S: C D 38$ transgenic plants ${ }^{21}$, respectively. Furthermore, whether $\mathrm{NAD}^{+}$per se moves systemically was tested by paper chromatography. As shown in Supplementary Fig. 2b, 
a

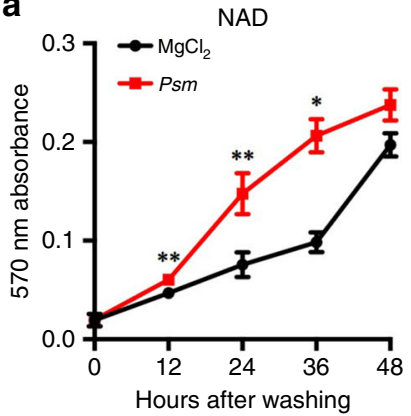

C

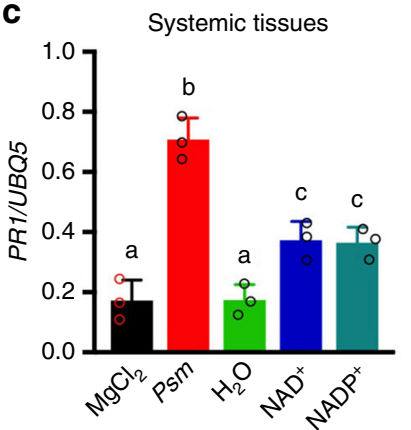

e

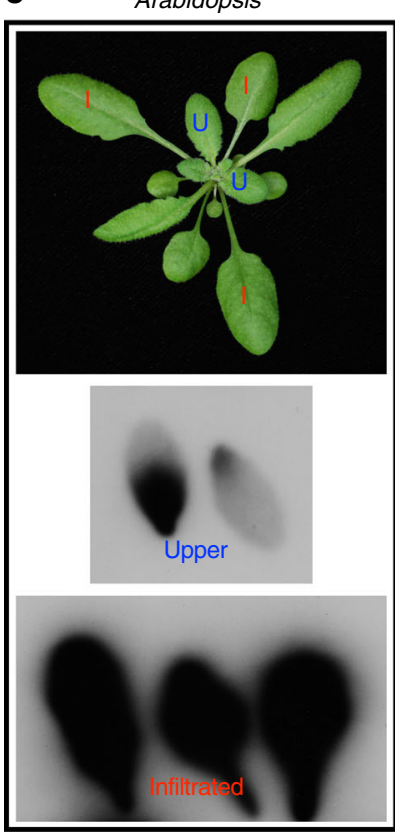

b

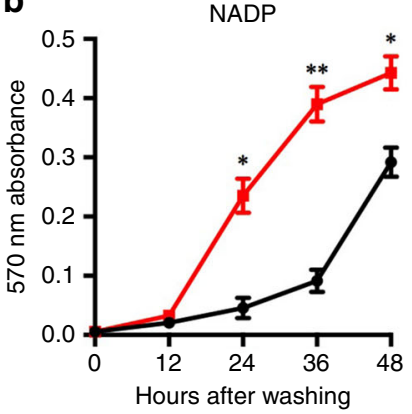

d

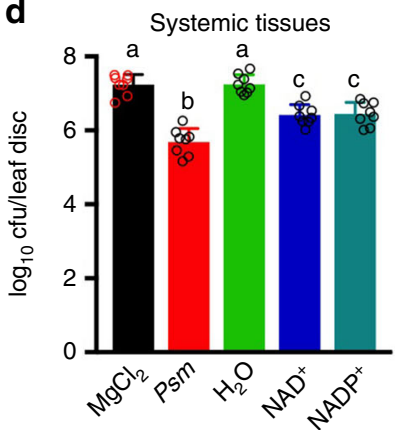

$\mathbf{f}$

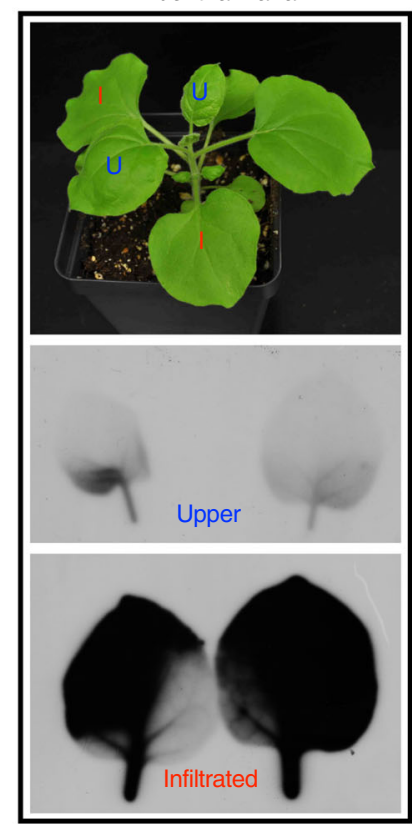

although three bands were detected in the extracts of local and systemic leaves, the predominant band has the same size as ${ }^{32} \mathrm{P}$ $\mathrm{NAD}^{+}$. This result supports the hypothesis that $\mathrm{NAD}^{+}$can be transported from local to systemic leaves. Interestingly, the signal intensity of the potential ${ }^{32} \mathrm{P}-\mathrm{NAD}^{+}$band in the extract of $35 \mathrm{~S}$ : CD38 systemic leaves was significantly reduced (Supplementary Fig. 2b), indicating that the movement of ${ }^{32} \mathrm{P}_{-N A D}{ }^{+}$in the $35 S$ : CD38 plants was inhibited. This observation is line with the previously reported result that SAR induction is partially compromised in $35 \mathrm{~S}: C D 38$ plants $^{21}$.

LecRK-VI.2 is a potential receptor for $\operatorname{eNAD}(\mathbf{P})+$. To convincingly demonstrate that $\mathrm{eNAD}(\mathrm{P})^{+}$is an SAR signal molecule, it is crucial to identify its receptors and test their role in SAR responses. We have previously identified LecRK-I.8 as a potential

Fig. 1 Induction of systemic resistance by exogenous $N A D(P)^{+}$and movement of exogenously applied NAD ${ }^{+}$. $\mathbf{a}, \mathbf{b} \mathrm{NAD} \mathbf{a}$ and NADP $\mathbf{b}$ leakage from the wild-type Col-0 leaves infiltrated with $10 \mathrm{mM} \mathrm{MgCl}_{2}$ (mock) or Psm $\left(\mathrm{OD}_{600}=0.002\right)$. One leaf disk was removed from each infiltrated leaf and sets of 10 leaf disks were submerged in $5 \mathrm{~mL}$ water in test tubes. NAD $(P)$ concentrations in the water were measured over time by enzymatic cycling assays. Data represent the mean \pm standard deviation (SD) of three biological replicates. Asterisks denote significant differences between Psmand $\mathrm{MgCl}_{2}$-treated samples ( ${ }^{\star} p<0.05,{ }^{\star \star} p<0.01$; Student's $t$ test).

c, $\mathbf{d}$ Expression of $P R 1 \mathbf{c}$ and growth of Psm $\mathbf{d}$ in the systemic leaves of the wild-type Col-O plants treated with $\mathrm{MgCl}_{2}, P s m, \mathrm{H}_{2} \mathrm{O}, \mathrm{NAD}^{+}$, or NADP+ For $\mathrm{MgCl}_{2}$ and $\mathrm{Psm}$ treatments, three lower leaves on each 4-week-old soilgrown Arabidopsis plant were infiltrated with $10 \mathrm{~mm} \mathrm{MgCl}$ or a Psm suspension $\left(\mathrm{OD}_{600}=0.002\right)$. Two days later, two systemic leaves were either collected for $P R 1$ expression analysis by qPCR $\mathbf{c}$ or challengeinoculated with Psm $\left(\mathrm{OD}_{600}=0.001\right) \mathbf{d}$. Three days later, eight leaves were collected to examine the growth of the pathogen. Alternatively, three lower leaves were infiltrated with $\mathrm{H}_{2} \mathrm{O}, 0.4 \mathrm{~mm} \mathrm{NAD}^{+}$, or $0.8 \mathrm{~mm} \mathrm{NADP}+$ every $12 \mathrm{hr}$ for a total of four times. About $5 \mathrm{hr}$ after the last infiltration, two systemic leaves were either collected for PR1 analysis c or challengeinoculated with Psm $\left(\mathrm{OD}_{600}=0.001\right) \mathbf{d}$. Expression levels of PR1 c were normalized against the constitutively expressed UBQ5. Data represent the mean \pm SD of three $\mathbf{c}$ or eight biological replicates $\mathbf{d}$. Different letters denote significant differences ( $p<0.05$; one-way ANOVA with Tukey's test). Compared with the strong systemic resistance induced by Psm ( 35fold decrease in Psm growth), $\mathrm{NAD}^{+}$and $\mathrm{NADP}^{+}$induced intermediate levels of resistance in the systemic leaves $(\sim 6.5$-fold decrease in $P$ sm growth). e, $\mathbf{f}$ Autoradiographic detection of ${ }^{32} \mathrm{P}$ in the systemic leaves of Arabidopsis e and $N$. benthamiana $\mathbf{f}$ plants with the lower leaves infiltrated with ${ }^{32} \mathrm{P}-\mathrm{NAD}^{+}$. Three lower leaves on an Arabidopsis plant or two lower leaves on a $N$. benthamiana plant were infiltrated with a water solution of

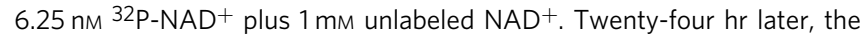
infiltrated leaves ( $\mathrm{I}$ in red) and two systemic leaves ( $U$ in blue) were collected and exposed to X-ray film

eNAD $^{+}$-binding receptor in Arabidopsis ${ }^{22}$. LecRK-I.8 binds $\mathrm{NAD}^{+}$with a dissociation constant $(\mathrm{K} d)$ of $436.5 \pm 104.8 \mathrm{~nm}$. Surprisingly, NADP ${ }^{+}$did not compete for binding of LecRK-I.8 with ${ }^{32} \mathrm{P}-\mathrm{NAD}^{+}$. In line with this result, mutations in LecRK-I.8 did not affect $\mathrm{NADP}^{+}$-induced immune responses. Furthermore, the lecrk-I.8 mutations compromised basal immunity but had no effect on biological induction of $\mathrm{SAR}^{22}$. These results prompted us to identify $\mathrm{eNADP}^{+}$-binding receptors. We have previously isolated transferred DNA (T-DNA) insertion lines for a group of receptor-like genes that were induced by exogenous $\mathrm{NAD}^{+22}$. We suspected that $\mathrm{NAD}^{+}$might also induce $\mathrm{eNADP}^{+}$-binding receptor genes and thus tested exogenous $\mathrm{NADP}^{+}$-induced Psm resistance in the T-DNA insertion lines. As shown in Supplementary Fig. 3a, NADP ${ }^{+}$-induced resistance was clearly reduced in the T-DNA insertion line SALK_070801, which harbors a T-DNA insertion in the gene At5g01540 that encodes LecRKVI.2. We then tested the transcript levels of LecRK-VI.2 in SALK_070801 and two more T-DNA insertion lines, SAIL_1146_B02 and SAIL_796_E11. Basal transcript levels of LecRK-VI.2 in the T-DNA insertion lines were $~ 33-48 \%$ of those in the wild type, indicating that all three T-DNA insertion lines are knockdown mutants of LecRK-VI.2 (Supplementary Fig. 3b, c). SALK_070801 has previously been named lecrk-VI.2-125, and we thus named SAIL_1146_B02 and SAIL_796_E11 lecrk-VI.2-2 and lecrk-VI.2-3, respectively (Supplementary Fig. 3b). Although previous work has shown that $\mathrm{NAD}^{+}$-induced resistance to Psm was not affected in the three lecrk-VI.2 alleles ${ }^{22}, \mathrm{NAD}^{+}$-induced expression of $P R 1, P R 2$, and $P R 5$ were all significantly inhibited with the exception of PR5 in lecrk-VI.2-3 (Fig. 2a-c). Importantly, 
a

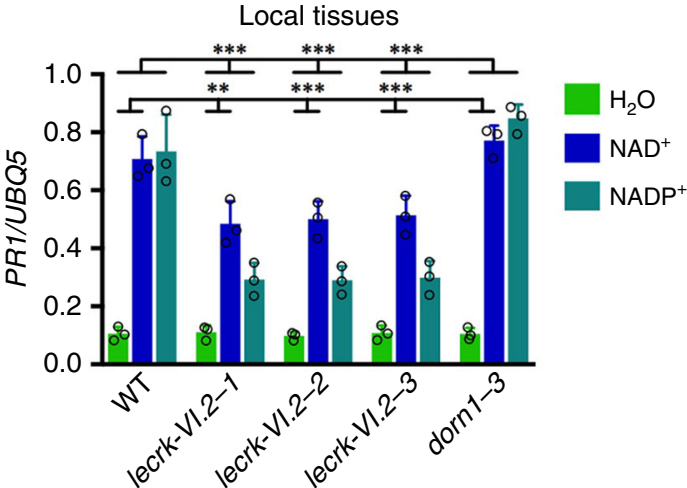

b

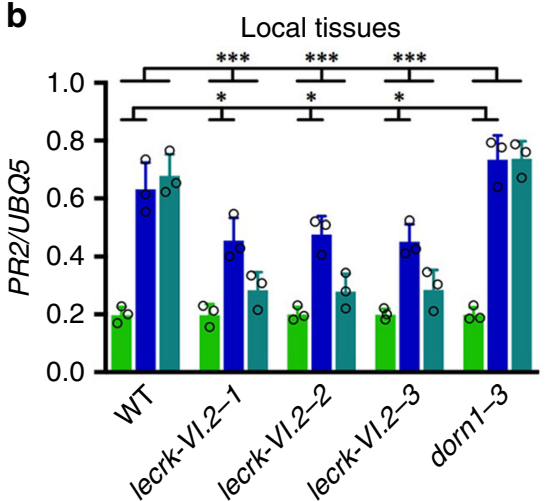

C

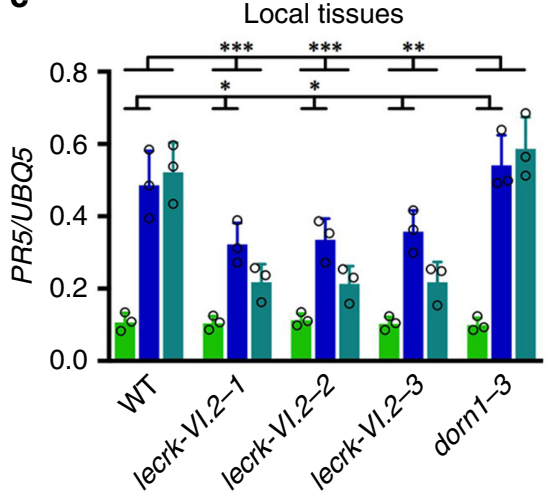

f

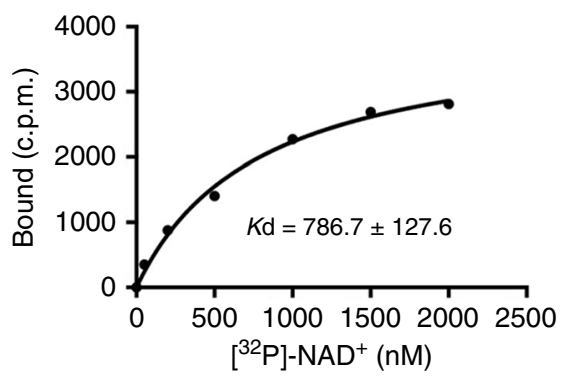

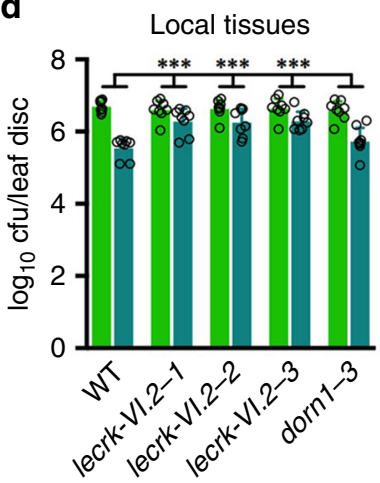

g

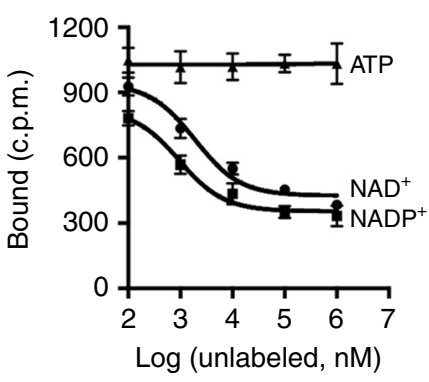

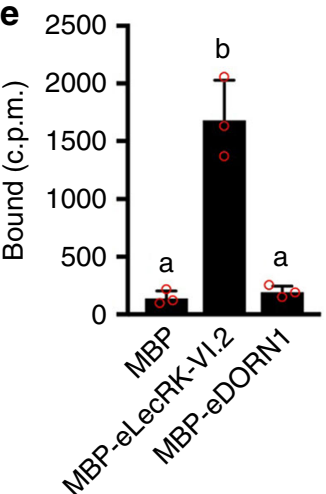

h

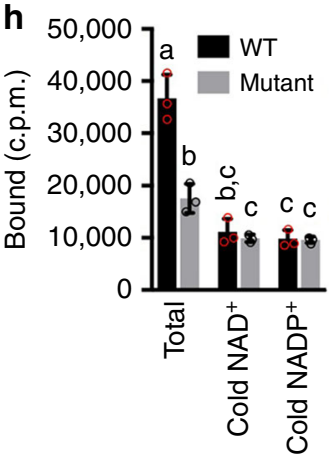

Fig. 2 Exogenous $N A D(P)^{+}$-induced local defense responses in the lecrk-VI.2 mutants and binding of $N A D(P){ }^{+}$to LecRK-VI.2. a-c Exogenous $N A D(P)^{+}-$ induced local expression of $P R 1 \mathbf{a}, P R 2 \mathbf{b}$, and $P R 5 \mathbf{c}$ in the wild-type (WT), lecrk-VI.2, and dorn1-3 plants. Leaves of 4-week-old soil-grown plants were infiltrated with $0.2 \mathrm{~mm} \mathrm{NAD}^{+}, 0.4 \mathrm{~mm} \mathrm{NADP}+$ or $\mathrm{H}_{2} \mathrm{O}$. The infiltrated leaves were collected $20 \mathrm{hr}$ later. Total RNA was extracted and subjected to qPCR analysis. Expression levels were normalized against the constitutively expressed UBQ5. Data represent the mean \pm SD of three biological replicates. Asterisks denote significant differences between the induction in the mutants and that in the wild type $\left({ }^{\star} p<0.05,{ }^{\star \star} p<0.01,{ }^{\star \star \star} p<0.001 ;\right.$ two-way ANOVA with Sidak's test). Upper line: induction by NADP+; lower line: induction by NAD+. $\mathbf{d}$ Exogenous NADP+-induced local resistance in the wild-type, lecrk-VI.2, and dorn1-3 plants. Leaves of 4-week-old soil-grown plants were infiltrated with $0.4 \mathrm{~mm} \mathrm{NADP}+$ or $\mathrm{H}_{2} \mathrm{O}$. Five hr later, the infiltrated leaves were inoculated with a Psm suspension $\left(\mathrm{OD}_{600}=0.001\right)$. Three d later, eight leaves were collected to examine the growth of the pathogen. Data represent the mean \pm SD of eight biological replicates. Asterisks denote significant differences between the induction in the mutants and that in the wild type ( ${ }^{\star \star \star} p<$ 0.001; two-way ANOVA with Sidak's test). e Binding of ${ }^{32} \mathrm{P}-\mathrm{NAD}^{+}$to recombinant MBP, MBP-eLecRK-VI.2, and MBP-eDORN1 proteins. Approximately $5 \mu \mathrm{g}$ recombinant proteins were used for each binding assay. Data represent the mean \pm SD of three experiments. Different letters denote significant differences ( $p<0.05$; one-way ANOVA with Tukey's test). f Saturation binding assay for LecRK-VI.2. Recombinant MBP-eLecRK-VI.2 proteins were incubated with the indicated concentrations of $32 \mathrm{P}-\mathrm{NAD}^{+}$for 30 min. Free NAD ${ }^{+}$was removed by washing. Data were plotted as a specific binding. The dissociation constant $(K d)$ was calculated by one site specific binding saturation model using GraphPad Prism 7 (www.graphgpad.com). The experiment was repeated four times with similar results and results from a representative experiment were presented. $\mathbf{g}$ Competitive binding assay for LecRK-VI.2. Samples containing $250 \mathrm{~nm}$ of ${ }^{32} \mathrm{P}-\mathrm{NAD}^{+}$in the presence of $100 \mathrm{~nm}$ to $1 \mathrm{~mm}$ of unlabeled nucleotides were assayed for specific binding of $32 \mathrm{P}-\mathrm{NAD}^{+}$. Data were plotted as a specific binding with SD of three experiments. The $50 \%$ inhibition concentration $\left(\mathrm{IC}_{50}\right)$ values were calculated in $\mathrm{GraphPad}$ Prism 7 using the one site Fit $\log \mathrm{C}_{50}$ competition model. $\mathbf{h}$ Binding of ${ }^{32} \mathrm{P}-\mathrm{NAD}+$ to the microsomal fractions of the wild-type (WT) and lecrk-VI.2-2 mutant plants.

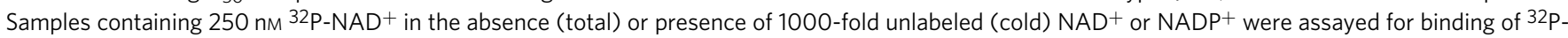
$\mathrm{NAD}^{+}$. Data represent the mean $\pm \mathrm{SD}$ of three experiments. Different letters denote significant differences $(p<0.05$; one-way ANOVA with Tukey's test) 
$\mathrm{NADP}^{+}$-induced $P R$ gene expression and $P s m$ resistance were significantly suppressed in all three alleles but not in the extracellular ATP receptor mutant dorn1-326 (Fig. 2a-d). These results suggest that LecRK-VI.2 may play a more important role in $\mathrm{eNADP}^{+}$signaling than in $\mathrm{eNAD}^{+}$signaling in the local leaves.

We then tested whether LecRK-VI.2 binds $\mathrm{NAD}^{+}$using ${ }^{32} \mathrm{P}-$ $\mathrm{NAD}^{+}$. The extracellular domain (amino acids (AAs) 23-310) of LecRK-VI.2 (eLecRK-VI.2) was expressed and purified from Escherichia coli as a recombinant maltose-binding protein (MBP) fusion (Supplementary Fig. 3d) and subjected to binding assays with ${ }^{32} \mathrm{P}-\mathrm{NAD}^{+}$. As shown in Fig. $2 \mathrm{e}$, a specific $\mathrm{NAD}^{+}$binding activity was detected for MBP-eLecRK-VI.2 but not for the simultaneously purified MBP and MBP-eDORN1 (AA 22-288) proteins. MBP-eLecRK-VI.2 exhibited a typical saturation curve for $\mathrm{NAD}^{+}$binding with a $\mathrm{Kd}$ of $786.7 \pm 127.6 \mathrm{~nm}$ (Fig. $2 \mathrm{f}$ ). To test whether LecRK-VI.2 binds NADP ${ }^{+}$, we compared the abilities of unlabeled $\mathrm{NAD}^{+}, \mathrm{NADP}^{+}$, and ATP to compete for binding of ${ }^{32} \mathrm{p}-\mathrm{NAD}^{+}$. Binding of ${ }^{32} \mathrm{P}-\mathrm{NAD}^{+}$to MBP-eLecRK-VI. 2 was effectively competed by unlabeled $\mathrm{NAD}^{+}(50 \%$ inhibition concentration, $\left.\mathrm{IC}_{50}, 1,887 \mathrm{nM}\right)$ and $\mathrm{NADP}^{+}\left(\mathrm{IC}_{50}, 945 \mathrm{nM}\right)$, but was not competed by ATP ( $\mathrm{IC}_{50}>100,000 \mathrm{~nm}$ ) (Fig. $2 \mathrm{~g}$ ). As the $\mathrm{IC}_{50}$ of $\mathrm{NADP}^{+}$is approximately half of that of $\mathrm{NAD}^{+}$, the relative binding affinity of $\mathrm{NADP}^{+}$is slightly higher than that of $\mathrm{NAD}^{+}$, which is in agreement with the compromised NADP ${ }^{+}$ responsiveness in the lecrk-VI.2 mutants (Fig. 2a-d). Furthermore, the total $\mathrm{NAD}^{+-}$binding activity in the membrane fractions of the lecrk-VI.2-2 mutant was significantly lower than that in the wild type, and the binding of ${ }^{32} \mathrm{P}_{-} \mathrm{NAD}^{+}$to the membrane fractions was also effectively competed by both unlabeled $\mathrm{NAD}^{+}$ and $\mathrm{NADP}^{+}$(Fig. 2h). Note that the reduced binding of ${ }^{32} \mathrm{P}$ $\mathrm{NAD}^{+}$to the membrane fractions of lecrk-VI.2-2 was further competed by unlabeled $\mathrm{NAD}^{+}$and $\mathrm{NADP}^{+}$, indicating the existence of other $\mathrm{NAD}(\mathrm{P})^{+}$-binding proteins. Taken together, these results indicate that LecRK-VI.2 is a potential receptor for both $\mathrm{NAD}^{+}$and $\mathrm{NADP}^{+}$. In agreement with this conclusion, the LecRK-VI.2 gene is induced by both $\mathrm{NAD}^{+}$and $\mathrm{NADP}^{+}$ (Supplementary Fig. 3e).

LecRK-VI.2 is required for $\mathrm{NAD}(\mathrm{P})^{+}$-induced systemic immunity. To test whether LecRK-VI.2 is essential for exogenous $\mathrm{NAD}(\mathrm{P})^{+}$to trigger systemic resistance, we infiltrated three lower leaves on each Arabidopsis plant with $0.4 \mathrm{mM} \mathrm{NAD}^{+}$or $0.8 \mathrm{~mm}$ $\mathrm{NADP}^{+}$every 12 hours for a total of four times. About 5 hours after the last infiltration, the systemic leaves were either collected for analysis of the induction of PR1 or challenge-inoculated with Psm to test $\mathrm{NAD}(\mathrm{P})^{+}$-induced systemic resistance. As shown Fig. 3a, b, although mutations in LecRK-VI.2 did not significantly inhibit $\mathrm{NAD}(\mathrm{P})^{+}$-induced $P R 1$ gene expression, $\mathrm{NAD}(\mathrm{P})^{+}$. induced resistance to Psm in the systemic leaves was completely blocked in the mutants plants. This result indicates that LecRKVI.2 is required for exogenous $\mathrm{NAD}(\mathrm{P})^{+}$-induced systemic resistance and further supports LecRK-VI.2 being an eNAD $(\mathrm{P})^{+}$ receptor.

To test the necessity of the well-documented SAR pathway genes in $\operatorname{eNAD}(\mathrm{P})^{+}$signaling, we first monitored exogenous $\mathrm{NAD}(\mathrm{P})^{+}$induced resistance to Psm in the local leaves of various SAR mutants. Interestingly, except fad7 (fatty acid desaturase 7$)^{27}$, only mutations affecting SA accumulation, including sid2 (SA induction deficient 2$)^{28}$, eds5 (enhanced disease susceptibility5) ${ }^{29}$, eds $1^{30}$, pad4

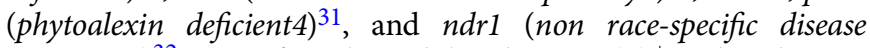
resistance 1$)^{32}$, significantly inhibited $\mathrm{NAD}(\mathrm{P})^{+}$-induced $P s m$ resistance (Supplementary Fig. 4a-d). The npr1-3 (nonexpressor of $P R$ genes 1-3) mutation, which largely blocks SA signaling ${ }^{33}$, significantly suppressed $\mathrm{NADP}^{+}$- but not $\mathrm{NAD}^{+}$-induced resistance (Supplementary Fig. 4a), which is consistent with the result obtained with the npr $1-1$ allele ${ }^{19}$. These results indicate that eNAD $(\mathrm{P})^{+}$activates SA-dependent signaling and may function downstream or independently of ALD1 (AGD2-Like Defense response protein1) ${ }^{34}$, FMO1 (Flavin-dependent Monooxygenase1) ${ }^{35}$, AZI1 (AZelaic acid Induced 1$)^{9}$, NHO1 (NONHOST1) ${ }^{36}$, PEPR1 (PEPP Receptor 1$) / 2^{37}$, DIR1, and SFD1 (Suppressor of Fatty acid desaturase Deficiency 1$)^{38}$ in the local leaves.

We further tested exogenous $\mathrm{NAD}(\mathrm{P})^{+}$-induced systemic resistance to Psm in the systemic leaves of sid2, ald $1^{34}, f m o 1^{35}$, and $n h o 1^{36}$, which do not accumulate SA, the putative SAR mobile signals Pip, NHP, and G3P, respectively, and $n p r 1$, azi $1^{9}$, and pepr1 pepr $2^{39}$, which do not respond to SA, the putative SAR signal molecule AzA, and Pep peptide elicitors, respectively. To this end, three lower leaves on each plant were infiltrated with $0.4 \mathrm{mM} \mathrm{NAD}^{+}$or $0.8 \mathrm{~mm} \mathrm{NADP}^{+}$every 12 hours for a total of four times. Five hours after the last infiltration, the systemic leaves were challenge-inoculated with $P s m$ to test $\mathrm{NAD}(\mathrm{P})^{+}$-induced systemic resistance. As shown in Fig. 3c, $\mathrm{NAD}(\mathrm{P})^{+}$-induced systemic resistance against Psm was significantly suppressed in sid2 and npr1, but not in ald1, fmo1, nho1, azi1, and pepr1 pepr2, indicating that $\mathrm{eNAD}(\mathrm{P})^{+}$-triggered systemic signaling requires SA and NPR1, but not Pip, NHP, G3P, AzA, and Pep peptide elicitors.

We have previously shown that high concentrations (>1 mM) of $\mathrm{NAD}(\mathrm{P})^{+}$significantly induce $\mathrm{SA}$ accumulation ${ }^{19}$. To test whether the concentrations used above could induce SA accumulation, free SA levels in leaf tissues treated with $0.4 \mathrm{~mm}$ $\mathrm{NAD}^{+}$or $0.8 \mathrm{~mm} \mathrm{NADP}^{+}$were measured. As shown in Supplementary Fig. 5a, $0.4 \mathrm{~mm} \mathrm{NAD}^{+}$and $0.8 \mathrm{~mm} \mathrm{NADP}^{+}$did not significantly induce free $\mathrm{SA}$ accumulation in the treated leaves, suggesting that basal SA is both necessary and sufficient for $\mathrm{eNAD}(\mathrm{P})^{+}$-induced defense signaling. On the other hand, previous microarray analysis indicated that SA treatment quickly (1 hour) induces LecRK-VI.2 expression ${ }^{40}$. We confirmed this result by quantitative PCR (qPCR) and further revealed that the induction depends on the transcription coactivator NPR1 (Supplementary Fig. 5b, c). These results indicate that SA signaling positively regulates LecRK-VI.2 expression, suggesting a signaling amplification loop comprising SA, NPR1, and LecRKVI.2.

LecRK-VI.2 is required for biological induction of SAR. If eNAD $(\mathrm{P})^{+}$is an SAR signal molecule and LecRK-VI.2 is a receptor of $\mathrm{eNAD}(\mathrm{P})^{+}$, mutations in LecRK-VI.2 should block biological induction of SAR. To test this hypothesis, we infiltrated three lower leaves on each plant with either $10 \mathrm{mM} \mathrm{MgCl}_{2}$ (-SAR) or Psm (+ SAR). Two days later, expression of $P R 1, P R 2$, and PR5 in the systemic leaves was analyzed. As shown in Fig. $4 \mathrm{a}-\mathrm{c}$, induction of the three commonly used SAR marker genes was significantly suppressed in the lecrk-VI.2 mutants, but not in dorn1-3. To test SAR activation-induced resistance in the lecrk-VI.2 plants, we challenge-inoculated the systemic leaves with Psm and determined the bacterial growth after 3 days. As shown in Fig. 4d, SAR activation induced strong resistance in the wild-type and dorn1-3 plants, whereas the resistance was significantly inhibited in the lecrk-VI.2 mutants. We further conducted a microarray experiment to compare SAR activationinduced transcriptome changes in lecrk-VI.2-2 and wild type (National Center for Biotechnology Information Gene Expression Omnibus series number GSE121886). Systemic leaf tissues were collected two days after inoculation of the lower leaves with Psm, as significant systemic increases in $P R$ gene expression and resistance were observed at this time point ${ }^{41}$ (Fig. $4 \mathrm{a}-\mathrm{d}$ ). Genes that were induced or suppressed twofold or higher with a low $q$ value $(\leq 0.05)$ by SAR activation in lecrk-VI.2-2 and the wild type 
a

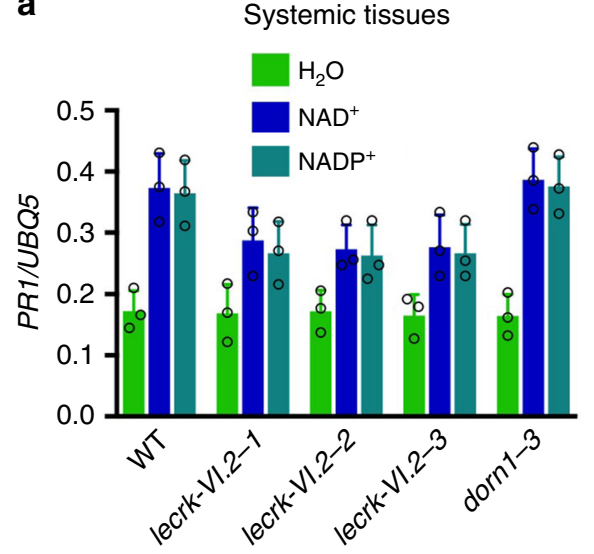

b

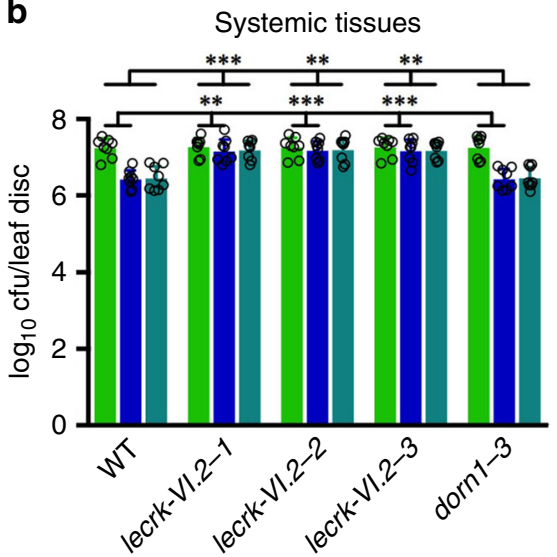

C

Systemic tissues

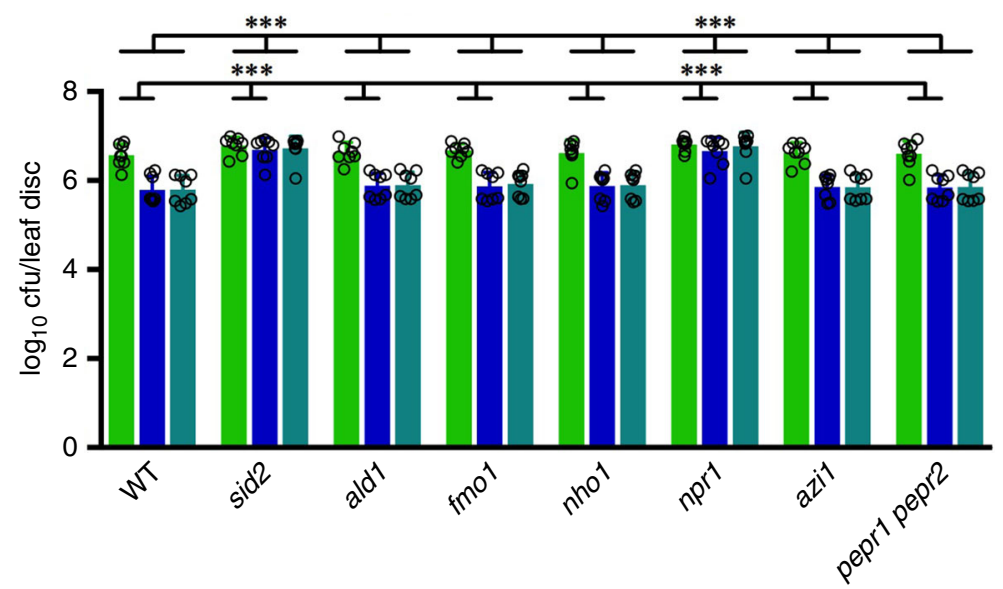

Fig. 3 Exogenous $N A D(P)^{+}$-induced systemic responses in lecrk-VI.2 and several SAR mutants. a, b $N A D(P)^{+}$-induced systemic $P R 1$ expression a and systemic resistance $\mathbf{b}$ in the wild-type (WT), lecrk-VI.2, and dorn1-3 plants. Three lower leaves on each 4-week-old soil-grown plant were infiltrated with $\mathrm{H}_{2} \mathrm{O}, 0.4 \mathrm{~mm} \mathrm{NAD}^{+}$, or $0.8 \mathrm{~mm} \mathrm{NADP}+$ every $12 \mathrm{hr}$ for a total of four times. About $5 \mathrm{hr}$ after the last infiltration, two systemic leaves were either collected for PR1 analysis a or challenge-inoculated with a Psm suspension $\left(\mathrm{OD}_{600}=0.001\right) \mathbf{b}$. Three d later, eight leaves were collected to examine the growth of the pathogen. Expression levels of $P R 1$ a were normalized against the constitutively expressed UBQ5. Data represent the mean \pm SD of three a or eight biological replicates $\mathbf{b}$. Asterisks denote significant differences between the induction in the mutants and that in the wild type $\left({ }^{\star \star} p<0.01\right.$, ${ }^{\star \star \star} p<0.001$; twoway ANOVA with Sidak's test). Upper line: induction by NADP+; lower line: induction by NAD ${ }^{+}$. c NAD(P)+-induced systemic resistance in the wild-type, sid2, ald1, fmo1, nho1, npr1, azi1, and pepr1 pepr2 plants. The experiment was conducted as in $\mathbf{b}$. Data represent the mean \pm SD of eight biological replicates. Asterisks denote significant differences between the induction in the mutants and that in the wild type (*** $p<0.001$; two-way ANOVA with Sidak's test). Upper line: induction by NADP+; lower line: induction by NAD+

were identified and compared. As shown in Fig. 4e, f, a total of 564 and 151 genes in the wild type were up- and downregulated, respectively, whereas only 55 and 26 genes in lecrk-VI.2-2 were up- and downregulated, respectively. In other words, transcript levels of $>90$ and $82 \%$ of the genes that were induced and suppressed, respectively, in the wild type were not significantly changed in the lecrk-VI.2-2 mutant. These results indicate that the eNAD $(\mathrm{P})^{+}$-binding receptor LecRK-VI.2 is a crucial component in the SAR signaling pathway.

BAK1 and BKK1 are required for $\operatorname{eNAD}(\mathrm{P})+$ signaling. It has previously been shown that LecRK-VI.2 has a positive role in PTI via constitutive association with the leucine-rich repeat receptor kinase (LRR-RK) PRR FLAGELLIN-SENSING2 (FLS2) ${ }^{25,42}$. Upon flagellin perception, FLS2 recruits its co-receptors BAK1 and BAK1-LIKE1 (BKK1), which phosphorylate their interacting receptor-like cytoplasmic kinase Botrytis-Induced Kinase1 (BIK1) to initiate the PTI signaling ${ }^{43-48}$. To test whether these wellestablished PTI signaling components function in $\operatorname{eNAD}(\mathrm{P})^{+}$ signaling, we tested exogenous $\mathrm{NAD}(\mathrm{P})^{+}$-induced immune responses in the bak1-5 $5^{49}, b k k 1^{50}, b a k 1-5 b k k 1^{49}$, fls2 efr (elongation factor Tu receptor $)^{51,52}$, and bik $1^{45}$ mutants. As shown in Fig. 5a, b and Supplementary Fig. 6a, b, NAD $(\mathrm{P})^{+}$-induced $P R$ gene expression and $P s m$ resistance were not significantly altered in the $f l s 2$ efr and bik1 mutants, whereas the induction was differentially affected by the $b a k 1-5$ and $b k k 1$ mutations. $\mathrm{NAD}^{+}$induced expression of $P R 1$ and $P R 2$ was significantly inhibited in $b a k 1-5, b k k 1$, and bak1-5 bkk1, but $\mathrm{NAD}^{+}$-induced expression of $P R 5$ and resistance to $P s m$ was only significantly repressed in the bak1-5 bkk1 double mutant. On the other hand, NADP ${ }^{+}$-induced $P R$ gene expression and Psm resistance were significantly suppressed in both single and double mutants. These results indicate that BAK1 and BKK1 play overlapping and independent roles in the $\mathrm{eNAD}(\mathrm{P})^{+}$signaling pathways.

BAK1 and BKK1 are required for biological induction of SAR. Since BAK1 and BKK1 function in $\mathrm{eNADP}^{+}$signaling, they may be required for SAR. To test this hypothesis, three lower leaves on each plant were infiltrated with either $10 \mathrm{mM} \mathrm{MgCl}_{2}$ (-SAR) or Psm (+SAR). Two days later, expression of PR1, 
a

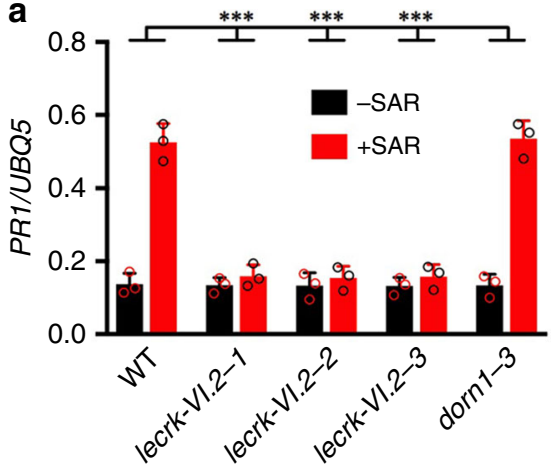

C

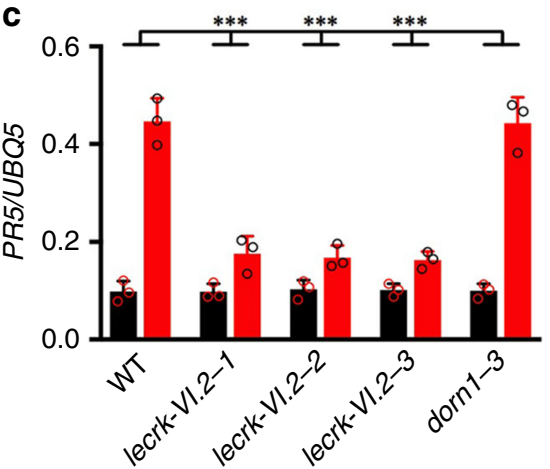

e

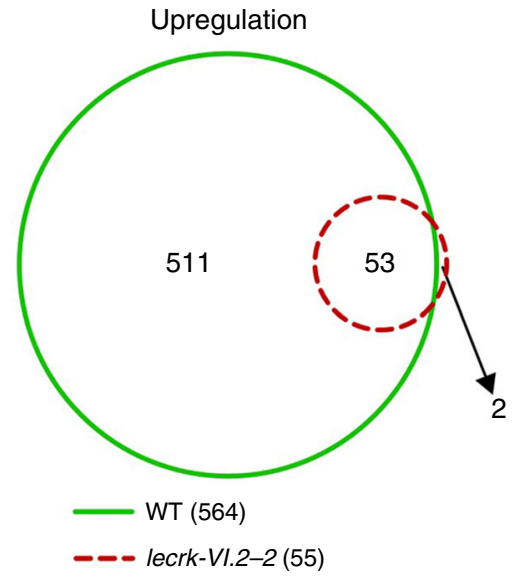

b

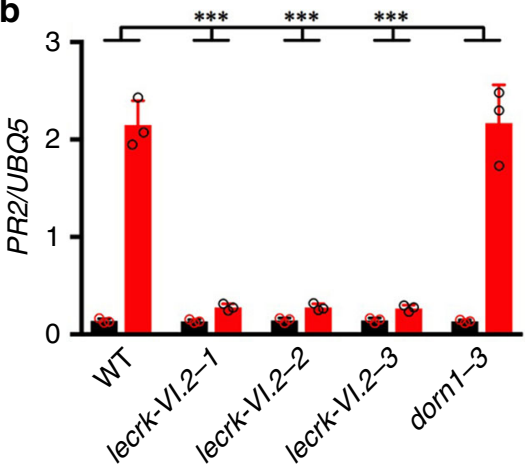

d

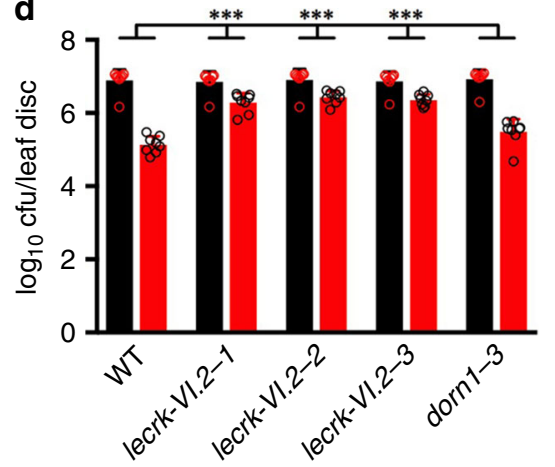

f

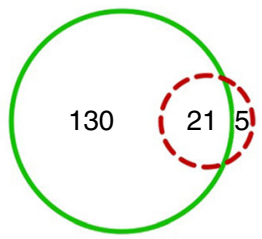

WT (551)

- lecrk-VI.2-2(26)

Fig. 4 Biological induction of SAR in the lecrk-VI.2 mutants. a-c Expression of $P R 1 \mathbf{a}, P R 2 \mathbf{b}$, and PR5 $\mathbf{c}$ in the systemic leaves of the wild-type (WT), lecrkVI.2, and dorn1-3 plants with or without SAR induction. Three lower leaves on each 4-week-old soil-grown plant were infiltrated with $10 \mathrm{~mm} \mathrm{MgCl}_{2}$ or a Psm suspension $\left(\mathrm{OD}_{600}=0.002\right)$. Two d later, systemic leaves were collected for $P R$ gene expression analysis by qPCR. Expression levels were normalized against the constitutively expressed UBQ5. Data represent the mean \pm SD of three biological replicates. Asterisks denote significant differences between the induction in the mutants and that in the wild type ( ${ }^{\star \star \star} p<0.001$; two-way ANOVA with Sidak's test). d Biological induction of SAR in the wild-type, lecrk-VI.2, and dorn1-3 plants. Three lower leaves on each 4-week-old soil-grown plant were infiltrated with $10 \mathrm{~mm} \mathrm{MgCl}_{2}$ or a $\mathrm{Psm}_{\mathrm{suspension}}\left(\mathrm{OD}_{600}=\right.$ 0.002). Two d later, two systemic leaves were challenge-inoculated with $P s m\left(O_{600}=0.001\right)$. Three d later, eight leaves were collected to examine the growth of the pathogen. Data represent the mean \pm SD of eight biological replicates. Asterisks denote significant differences between the induction in the mutants and that in the wild type ( ${ }^{\star *} p<0.001$; two-way ANOVA with Sidak's test). e, f Overlaps between the genes that were up-e or downregulated $\mathbf{f}$ in the systemic leaves of the wild-type and lecrk-VI.2-2 plants. Plants were treated as in a-c. Total RNA extracted from the systemic tissues was subjected to microarray analysis. Genes with an absolute fold change $\geq 2$ and a $q$ value $\leq 0.05$ were compared with obtain overlapped genes among the wild-type and lecrk-VI.2-2 plants

$P R 2$, and $P R 5$ in the systemic leaves was analyzed. Induction of the three $P R$ genes was significantly reduced in the bak1-5, $b k k 1$, and bak1-5 bkk1 mutants (Fig. 5c and Supplementary Fig. $6 c, d)$. We also challenge-inoculated the systemic leaves with $P s m$ and determined in planta bacterial titers after 3 days. As shown in Fig. 5d, SAR activation induced strong resistance in the wild-type, $f l s 2 \mathrm{efr}$, and $b i k 1$ plants, whereas the resistance was significantly compromised in the bak1-5, bkk1, and bak1-5 bkk1 mutants. We have included the bak1-5 mutant in the microarray experiment described above (Fig. 4e, f) to compare SAR activation-induced transcriptome changes in bak1-5 with those in lecrk-VI.2-2 and the wild type. Genes that were induced or suppressed twofold or higher with a low $q$ value $(\leq 0.05)$ by SAR activation in bak1-5 were identified and compared with those in the wild type and lecrk-VI.2-2. As shown in Fig. 5e, f, a total of 221 and 121 genes were up- and 
a

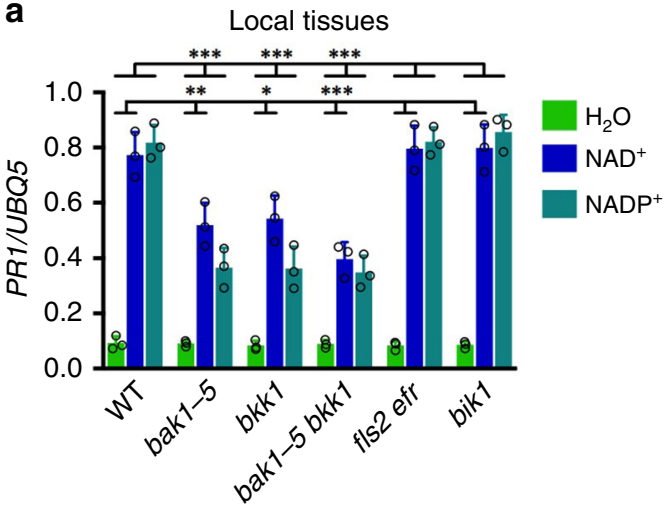

C

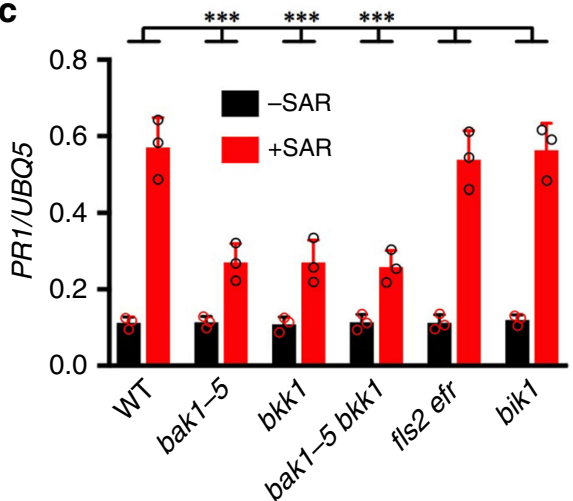

e

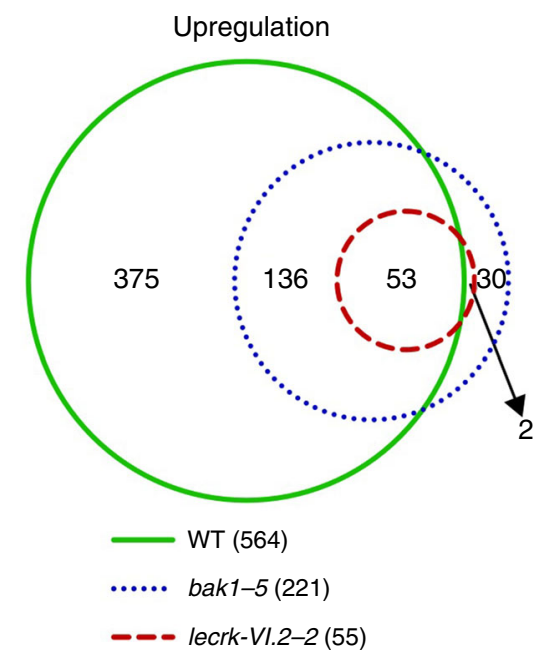

downegulated, respectively, in bak1-5, which fall between the numbers of genes that were up- and downregulated in the wild type and lecrk-VI.2-2. Furthermore, the majority of the genes that were induced or suppressed twofold or higher with a low $q$ value $(\leq 0.05)$ in the wild type were induced or suppressed to a smaller extent in bak1-5 and the smallest extent in lecrk-VI.2-2 (Supplementary Fig. 7 and Supplementary Data 1). These results indicate that the bak1-5 mutation suppressed SAR activation-induced signaling, but the strength of the suppression was not as strong as that in lecrk-VI.2-2, which may be attributed to the presence of BKK1 that might have some redundant functions with BAK1 in biological induction of SAR (Fig. 5d).

LecRK-VI.2 and BAK1 form a complex in vivo. As both LecRKVI.2 and BAK1 function in $\operatorname{eNAD}(\mathrm{P})^{+}$signaling and biological b

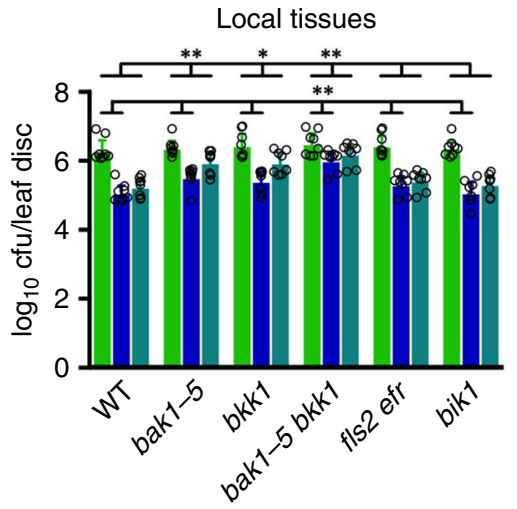

d

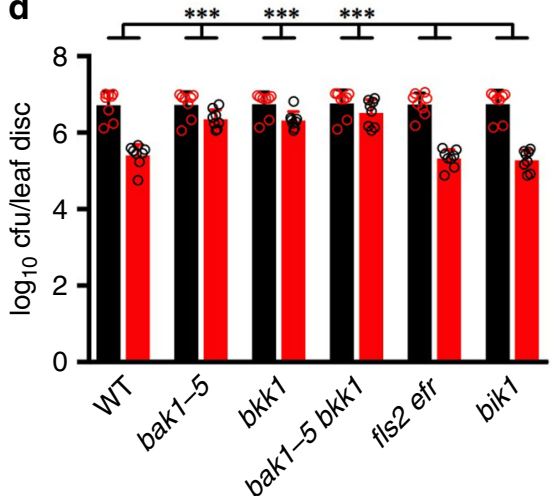

$\mathbf{f}$

Downregulation

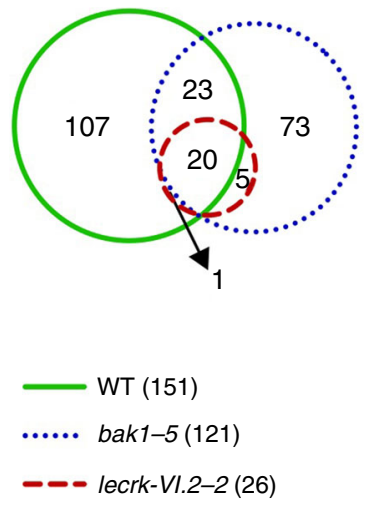

induction of SAR, they may form a protein complex. To test this hypothesis, we examined the interaction between the two proteins using three different approaches. First, we used pull-down assays to investigate possible interaction between the cytoplasmic kinase domains (KDs) of LecRK-VI.2 and BAK1 (LecRK-VI.2KD and BAK1KD, respectively). As shown in Fig. 6a and Supplementary Fig. 8a, amylose beads pulled down both MBP-LecRK-VI.2KD and GST-BAK1KD from a mixture of purified MBP-LecRKVI.2KD and GST-BAK1KD, but only pulled down MBP from a mixture of purified MBP and GST-BAK1KD or MBP-LecRKVI.2KD from a mixture of purified MBP-LecRK-VI.2KD and GST. This result indicates that LecRK-VI.2KD can physically interact with BAK1KD in vitro. Second, we employed the coimmunoprecipitation (Co-IP) technique in N. benthamiana to test possible association of LecRK-VI.2 with BAK1 in vivo. As shown in Fig. 6b, anti-FLAG beads precipitated both LecRK-VI.2- 
Fig. 5 Exogenous $N A D(P)^{+}$-induced local immune responses and biological induction of SAR in several PTI mutants. a Exogenous $N A D(P)^{+}$-induced local PR1 expression in the wild-type (WT), bak1-5, bkk1, bak1-5 bkk1, fls2 efr, and bik1 plants. Leaves of 4-week-old soil-grown plants were infiltrated with 0.2 mm $\mathrm{NAD}^{+}, 0.4 \mathrm{~mm} \mathrm{NADP}+$ or $\mathrm{H}_{2} \mathrm{O}$. The infiltrated leaves were collected $20 \mathrm{hr}$ later. Total RNA was extracted and subjected to qPCR analysis. Expression levels of $P R 1$ were normalized against the constitutively expressed UBQ5. Data represent the mean \pm SD of three biological replicates. Asterisks denote significant differences between the induction in the mutants and that in the wild type $\left({ }^{\star} p<0.05,{ }^{\star \star} p<0.01,{ }^{\star \star \star} p<0.001\right.$; two-way ANOVA with Sidak's test). Upper line: induction by NADP+; lower line: induction by NAD+ ${ }^{+}$. b Exogenous NAD(P)+-induced local resistance in the wild-type, bak1-5, bkk1, bak1-5 $b k k 1$, fls2 efr, and bik1 plants. Leaves of 4-week-old soil-grown plants were infiltrated with $0.2 \mathrm{~mm} \mathrm{NAD+}, 0.4 \mathrm{~mm} \mathrm{NADP}^{+}$or $\mathrm{H}_{2} \mathrm{O}$. Five hr later, the infiltrated leaves were inoculated with a Psm suspension $\left(\mathrm{OD}_{600}=0.001\right)$. Three $d$ later, eight leaves were collected to examine the growth of the pathogen. Data represent the mean \pm SD of eight biological replicates. Asterisks denote significant differences between the induction in the mutants and that in the wild type $\left({ }^{\star} p<0.05,{ }^{\star \star} p<0.01\right.$; two-way ANOVA with Sidak's test). Upper line: induction by NADP+; lower line: induction by NAD ${ }^{+}$.

c Expression of PR1 in the systemic leaves of the wild-type, bak1-5, bkk1, bak1-5 bkk1, fls2 efr, and bik1 plants with or without SAR induction. Three lower leaves on each 4-week-old soil-grown plant were infiltrated with $10 \mathrm{~mm} \mathrm{MgCl} 2$ or a Psm suspension $\left(\mathrm{OD}_{600}=0.002\right)$. Two d later, systemic leaves were collected for $P R 1$ expression analysis by qPCR. Data represent the mean \pm SD of three biological replicates. Asterisks denote significant differences between the induction in the mutants and that in the wild type ( ${ }^{\star \star \star} p<0.001$; two-way ANOVA with Sidak's test). d Biological induction of SAR in the wild-type, bak1-5, bkk1, bak1-5 bkk1, fls2 efr, and bik1 plants. Three lower leaves on each 4-week-old soil-grown plant were infiltrated with $10 \mathrm{~mm} \mathrm{MgCl}_{2}$ or a Psm suspension $\left(\mathrm{OD}_{600}=0.002\right)$. Two d later, two systemic leaves were challenge-inoculated with $P_{s m}\left(\mathrm{OD}_{600}=0.001\right)$. Three $d$ later, eight leaves were collected to examine the growth of the pathogen. Data represent the mean \pm SD of eight biological replicates. Asterisks denote significant differences between the induction in the mutants and that in the wild type ( ${ }^{\star \star \star} p<0.001$; two-way ANOVA with Sidak's test). e, f Overlaps among the genes that were up- or downregulated $\mathbf{f}$ in the systemic leaves of the wild-type, bak1-5, and lecrk-VI.2-2 plants. Plants were treated as in c. Total RNA extracted from the systemic tissues was subjected to microarray analysis. Genes with an absolute fold change $\geq 2$ and a $q$ value $\leq 0.05$ were compared with obtain overlapped genes among the wild-type, bak1-5, and lecrk-VI.2-2 plants

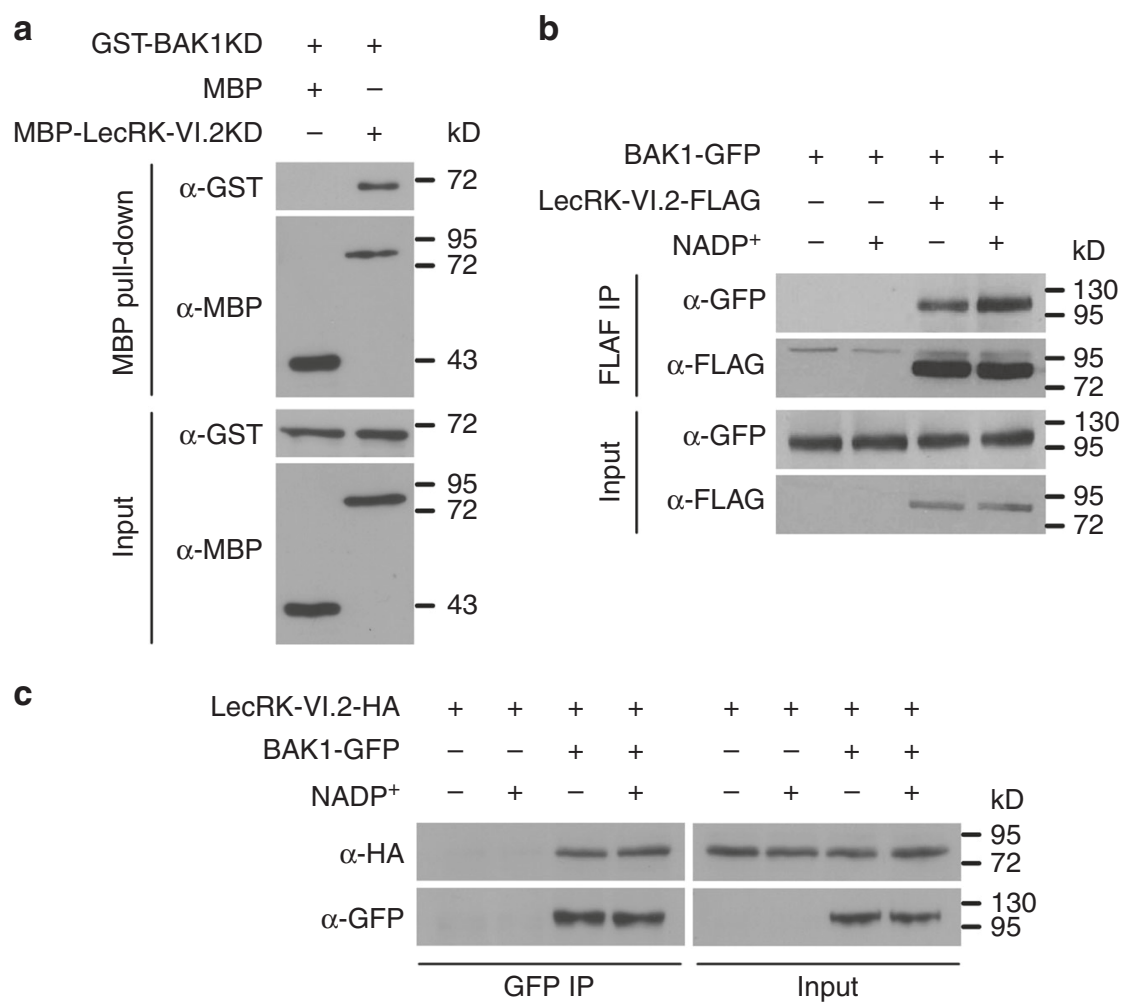

Fig. 6 Physical association between LecRK-VI.2 and BAK1. a In vitro maltose-binding protein (MBP) pull-down assay of LecRK-VI.2KD interaction with BAK1KD. Recombinant MBP or MBP-LecRK-VI.2KD was incubated with GST-BAK1KD and pulled down with amylose resin beads. Input and bead-bound proteins were analyzed by immunoblotting with monoclonal anti-MBP and anti-GST antibodies. b Co-immunoprecipitation (Co-IP) analysis of LecRK-VI.2FLAG association with BAK1-GFP in N. benthamiana. Total proteins (input) of N. benthamiana leaves transiently co-expressing LecRK-VI.2-FLAG and BAK1GFP, or transiently expressing BAK1-GFP alone, were immunoprecipitated with anti-FLAG affinity agarose beads and the precipitates were analyzed by immunoblotting with monoclonal anti-FLAG and anti-GFP antibodies. The leaves were treated with (+) or without (-) $0.8 \mathrm{~mm} \mathrm{NADP+}$ for 10 min. c Co-IP analysis of LecRK-VI.2-HA association with BAK1-GFP in Arabidopsis. Total proteins of Arabidopsis leaves from the BAK1:BAK1-GFP/LecRK-VI.2:LecRK-VI.2$H A$ transgenic plants were immunoprecipitated with monoclonal anti-GFP antibody/protein $\mathrm{G}$ plus agarose and the precipitates were analyzed by immunoblotting with polyclonal anti-GFP and monoclonal anti-HA antibodies. The leaves were treated with (+) or without $(-) 0.8$ mM NADP + for 10 min

FLAG and BAK-GFP (green fluorescence protein) from N. benthamiana transiently co-expressing the LecRK-VI.2-FLAG and BAK1-GFP fusion proteins, and $\mathrm{NADP}^{+}$treatment did not affect the amount of precipitated BAK1-GFP. In contrast, anti-FLAG beads did not precipitate BAK1-GFP from $N$. benthamiana transiently expressing BAK1-GFP only (Fig. 6b), indicating that BAK1-GFP did not bind nonspecifically to the anti-FLAG beads. Similarly, anti-FLAG beads precipitated LecRK-VI.2-FLAG and 
BAK1-GFP but not plasma membrane localized LTI6B-GFP53 (Supplementary Fig. 8b), excluding the possibility of nonspecific interaction with GFP. These results indicate that LecRK-VI.2-HA and BAK1-GFP constitutively associate with each other when transiently expressed in $N$. benthamiana. Finally, we created stable transgenic Arabidopsis plants co-expressing LecRK-VI.2HA and BAK1-GFP by transforming a LecRK-VI.2:LecRK-VI.2$H A$ construct into the previously characterized BAK1:BAK1-GFP plants $^{54}$. The LecRK-VI.2:LecRK-VI.2-HA construct was also transformed into wild type to generate plants expressing LecRKVI.2-HA only as a control. Co-IP experiments were conducted using these plants to test the association between LecRK-VI.2-HA and BAK1-GFP. As shown in Fig. 6c, anti-GFP/protein G plus agarose precipitated both BAK1-GFP and LecRK-VI.2-HA from the BAK1:BAK1-GFP/LecRK-VI.2:LecRK-VI.2-HA plants, and $\mathrm{NADP}^{+}$treatment did not increase the amount of LecRK-VI.2HA. On the other hand, anti-GFP/protein G plus agarose did not precipitate any lecRK-VI.2-HA from plants carrying the LecRKVI.2:LecRK-VI.2-HA transgene only. Taken together, these results demonstrate that LecRK-VI.2 and BAK1 constitutively form a protein complex in vivo.

To confirm that LecRK-VI.2 and BAK1 function through a protein complex in $\mathrm{NAD}(\mathrm{P})^{+}$signaling and $\mathrm{SAR}$, we generated a lecrk-VI.2 bak1 double mutant by crossing lecrk-VI.2-2 with bak15 and tested its responses to exogenous $\mathrm{NADP}^{+}$treatment and biological induction of SAR. As shown in Supplementary Fig. 9a, $\mathrm{b}, \mathrm{NADP}^{+}$-induced and SAR activation-conferred resistance to Psm was comparable in the lecrk-VI.2 bak1 double mutant and the lecrk-VI.2-2 single mutant. This result indicates no additive effect between the lecrk-VI.2-2 and bak1-5 mutations, supporting that LecRK-VI.2 and BAK1 function in SAR by constituting a protein complex.

The importance of the kinase activity of LecR-VI.2 and BAK1. To determine whether phosphorylation is involved in LecRKVI.2/BAK1-mediated signaling, we tested if the kinase activities of LecRK-VI.2 and BAK1 are required for their functions in $\mathrm{eNADP}^{+}$signaling and biological induction of SAR. To this end, a point mutation was introduced into the LecRK-VI.2:LecRK-VI.2$H A$ construct to replace a conserved Asp (D) residue at the position 494 of the catalytic loop HRD motif with an Asn $(\mathrm{N})$ residue. The resulting construct (LecRK-VI.2:lecrk-VI.2(D494N)$H A)$ and the wild-type construct were then transformed into the lecrk-VI.2-2 background. As shown in Fig. 7a-c and Supplementary Fig. 10a, the wild-type construct LecRK-VI.2:LecRK-VI.2-HA almost completely complemented the defects of lecrk-VI.2-2 in $\mathrm{NADP}^{+}$-induced $P R$ gene expression and $P s m$ resistance as well as biological induction of SAR, whereas the LecRK-VI.2:lecrk-VI.2 (D494N)-HA construct did not rescue any of these defects. For BAK1, we transformed the 35 S:BAK1-GFP construct and a 35 S: bak1(K317E)-GFP construct into the bak1-5 background. The K317E mutation has been shown to abolish the kinase activity of BAK1 ${ }^{54,55}$. Although it has been shown that BAK1-GFP is not fully functional in PTI responses and bak1-5 is a dominantnegative mutation 49,56 , the $35 \mathrm{~S}: B A K 1-G F P$ construct largely complemented the bak1-5 mutant phenotypes including reduced induction of $P R$ gene expression and $P s m$ resistance by $\mathrm{NADP}^{+}$as well as compromised SAR (Fig. 7d-f and Supplementary Fig. 10b). To exclude the possibility of seed contamination or transgene modification, we confirmed the bak1-5 genetic background of the transgenic plants and the inability of BAK1-GFP to complement bak1-5 in flg22-induced ROS burst (Supplementary Fig. 11a, b). Therefore, C-terminal-tagged BAK1 is still functional in NADP ${ }^{+}$ signaling and SAR. On the other hand, the 35 S:bak1(K317E)-GFP construct did not complement any of the bak1-5 phenotypes a
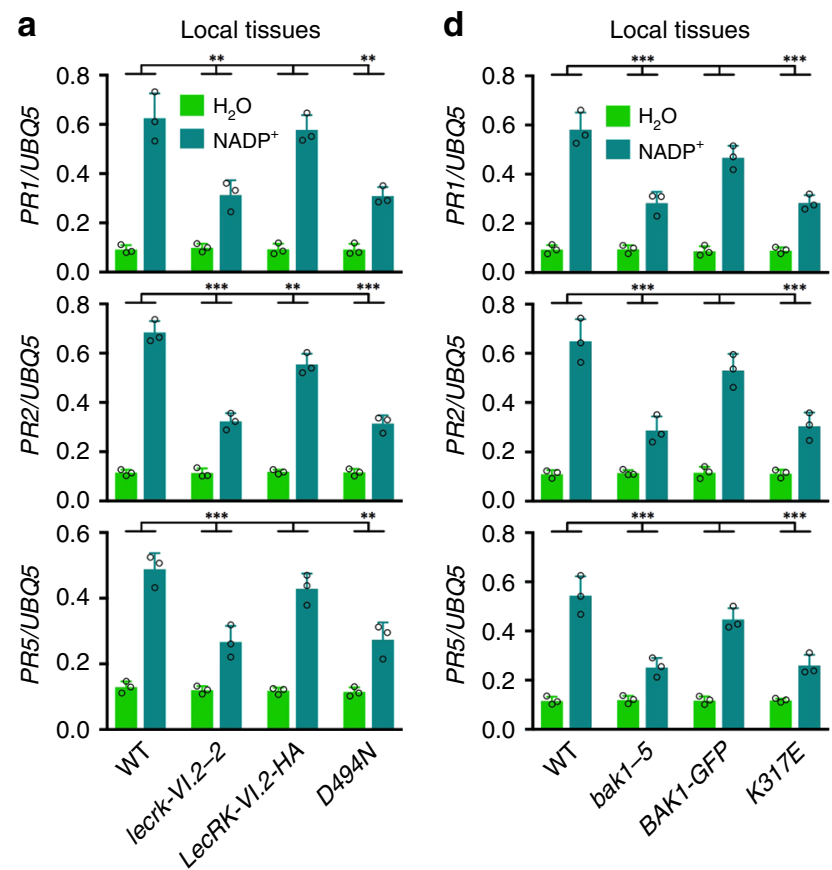

b

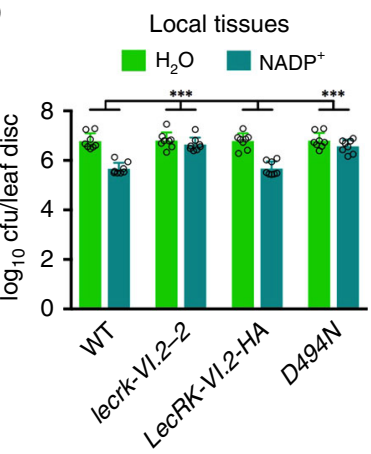

e
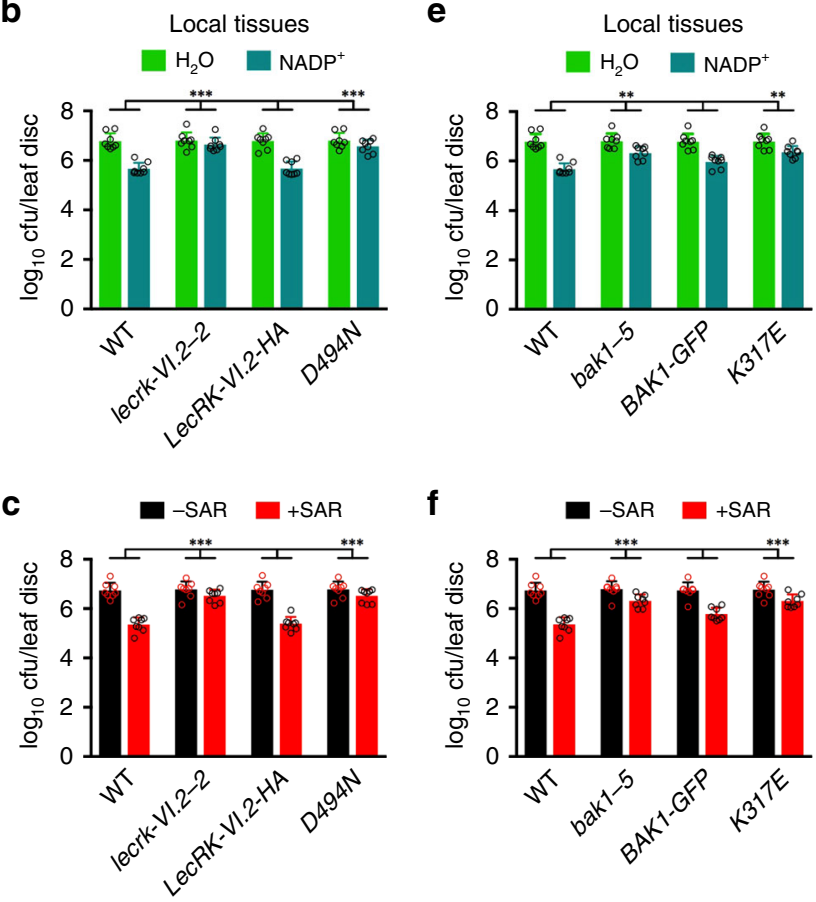

(Fig. 7d-f and Supplementary Fig. 10b). Taken together, these results demonstrate that the kinase activities of both LecRK-VI.2 and $\mathrm{BAK} 1$ are required for $\mathrm{eNADP}^{+}$-induced immune responses and biological induction of SAR, suggesting that phosphorylation is involved in LecRK-VI.2/BAK1-mediated eNADP ${ }^{+}$and SAR signaling.

LecRK-VI.2 is required for flg22-induced systemic immunity. It has been shown that LecRK-VI.2 contributes to PTI responses including flg22 (a 22-amino acid peptide corresponding to the $\mathrm{N}$ terminus of bacterial flagellin)-induced MPK3/6 activation, callose deposition, and stomatal closure ${ }^{25}$. Consistently, the lecrkVI.2-1 mutant plants are highly sensitive to P. syringae pv. tomato DC3000 when plants are dip inoculated ${ }^{25}$. To explore possible 
Fig. 7 The necessity of the kinase activities of LecRK-VI.2 and BAK1 in $\mathrm{eNADP}^{+}$signaling and SAR. a Exogenous NADP ${ }^{+}$-induced local expression of $P R 1, P R 2$, and PR5 in the wild-type (WT), lecrk-VI.2-2, LecRK-VI.2:LecRKVI.2-HA, and LecRK-VI.2:lecrk-VI.2(D494N)-HA plants. Leaves of 4-week-old soil-grown plants were infiltrated with $0.4 \mathrm{~mm} \mathrm{NADP}+$ or $\mathrm{H}_{2} \mathrm{O}$. The infiltrated leaves were collected $20 \mathrm{hr}$ later. Total RNA was extracted and subjected to GPCR analysis. Expression levels were normalized against the constitutively expressed UBQ5. Data represent the mean \pm SD of three biological replicates. Asterisks denote significant differences between the induction in the mutant or transgenic plants and that in the wild type $\left(^{\star \star} p<\right.$ $0.01,{ }^{\star \star \star} p<0.001$; two-way ANOVA with Sidak's test). b Exogenous $\mathrm{NADP}^{+}$-induced local resistance in the wild-type, lecrk-VI.2-2, LecRK-VI.2: LecRK-VI.2-HA, and LecRK-VI.2:lecrk-VI.2(D494N)-HA plants. Leaves of 4week-old soil-grown plants were infiltrated with $0.4 \mathrm{mM} \mathrm{NADP}^{+}$or $\mathrm{H}_{2} \mathrm{O}$. Five $\mathrm{hr}$ later, the infiltrated leaves were inoculated with a Psm suspension $\left(\mathrm{OD}_{600}=0.001\right)$. Three d later, eight leaves were collected to examine the growth of the pathogen. Data represent the mean \pm SD of eight biological replicates. Asterisks denote significant differences between the induction in the mutant or transgenic plants and that in the wild type $\left({ }^{* \star} p<0.001\right.$; twoway ANOVA with Sidak's test). c Biological induction of SAR in the wildtype, lecrk-VI.2-2, LecRK-VI.2:LecRK-VI.2-HA, and LecRK-VI.2:lecrk-VI.2 (D494N)-HA plants. Three lower leaves on each 4-week-old soil-grown plant were infiltrated with $10 \mathrm{mM} \mathrm{MgCl} 2$ or a Psm suspension $\left(\mathrm{OD}_{600}=\right.$ 0.002). Two d later, two systemic leaves were challenge-inoculated with Psm $\left(\mathrm{OD}_{600}=0.001\right)$. Three $d$ later, eight leaves were collected to examine the growth of the pathogen. Data represent the mean \pm SD of eight biological replicates. Asterisks denote significant differences between the induction in the mutant or transgenic plants and that in the wild type $\left({ }^{\star \star \star} p<0.001\right.$; two-way ANOVA with Sidak's test). d Exogenous NADP +induced local expression of $P R 1, P R 2$, and $P R 5$ in the wild-type, bak1-5, $35 \mathrm{~S}$ : BAK1-GFP, and 35 S:bak1(K317E)-GFP plants. The experiment was conducted as in a. Data represent the mean \pm SD of three biological replicates. Asterisks denote significant differences between the induction in the mutant or transgenic plants and that in the wild type ${ }^{\star \star \star} p<0.001$; twoway ANOVA with Sidak's test). e Exogenous NADP+-induced local resistance in the wild-type, bak1-5, 35 S:BAK1-GFP, and 35 S:bak1(K317E)-GFP plants. The experiment was conducted as in $\mathbf{b}$. Data represent the mean \pm SD of eight biological replicates. Asterisks denote significant differences between the induction in the mutant or transgenic plants and that in the wild type (** $p<0.01$; two-way ANOVA with Sidak's test). f Biological induction of SAR in the wild-type, bak1-5, 35 S:BAK1-GFP, and 35 S:bak1 (K317E)-GFP plants. The experiment was conducted as in c. Data represent the mean \pm SD of eight biological replicates. Asterisks denote significant differences between the induction in the mutant or transgenic plants and that in the wild type $\left({ }^{\star \star \star} p<0.001\right.$; two-way ANOVA with Sidak's test)

relationship between $\mathrm{eNAD}(\mathrm{P})^{+}$and flg22, we tested flg22induced local apoplastic and systemic resistance in the eNAD $(\mathrm{P})^{+}$ receptor mutants. To this end, we first generated a lecrk-I.8 lecrkVI.2 (lecrkI.8/VI.2) double mutant by crossing lecrk-I.8-2 with lecrk-VI.2-2 and tested its responses to exogenous $\mathrm{NAD}(\mathrm{P})^{+}$ treatment and biological induction of SAR. The double mutant behaved like lecrk-I.8-2 upon $\mathrm{NAD}^{+}$treatment and like lecrkVI.2-2 upon $\mathrm{NADP}^{+}$treatment or SAR induction (Supplementary Fig. 12a-c), suggesting that mutations in LecRK-I.8 and LecRK-VI.2 inhibit eNAD ${ }^{+}$and $\mathrm{eNADP}^{+}$signaling, respectively. We then tested flg22-induced local apoplastic resistance in the double mutant. As shown in Supplementary Fig. 12d, $100 \mathrm{~nm}$ flg22 induced similar levels of resistance to Psm in the wild-type, lecrk-I.8-2, lecrk-VI.2-2, and lecrkI.8/VI.2 plants. Finally, we examined flg22-induced systemic immunity in the lecrk-VI.2 single mutants, as the lecrk-I.8-2 mutation did not affect SAR ${ }^{22}$ (Supplementary Fig. 12c). To this end, three lower leaves on each plant were infiltrated with $200 \mathrm{~nm}$ flg22 every 12 hours for a total of 4 times. Five hours after the last infiltration, the systemic leaves were challenge-inoculated with Psm to test flg22-induced resistance. As shown in Supplementary Fig. 12e, flg22-induced systemic resistance was significantly inhibited in the three lecrk-VI.2 mutants. Therefore, LecRK-VI.2 is crucial for flg22-induced systemic immunity but not for flg22-induced local apoplastic resistance.

\section{Discussion}

Although it has been well documented in animals that $\operatorname{eNAD}(\mathrm{P})^{+}$ functions in numerous physiopathological processes ${ }^{18}, \mathrm{eNAD}(\mathrm{P})^{+}$ and its signaling role in plants have not been established. The identification of the first $\mathrm{eNAD}^{+}$-binding receptor in Arabidopsis has stimulated us to begin investigating this interesting molecule in depth ${ }^{22}$. Here, we identified LecRK-VI.2 as a potential primary eNAD $(\mathrm{P})^{+}$-binding receptor, which allowed us to uncover the LecRK-VI.2/BAK1 complex that has a central role in the establishment of SAR in Arabidopsis.

Several lines of evidence generated in this study suggest that eNAD $(\mathrm{P})^{+}$may be an SAR signal molecule in Arabidopsis. First, $\mathrm{NAD}(\mathrm{P})^{+}$continuously leaks into the extracellular space during pathogen infection (Fig. 1a, b). Second, local application of physiological concentrations of $\mathrm{NAD}(\mathrm{P})^{+}$induces resistance in the systemic leaves (Fig. 1c, d). Third, mutations in the potential eNAD $(\mathrm{P})^{+}$-binding receptor LecRK-VI.2 significantly inhibit SAR induction (Fig. 4). And fourth, BAK1 and BKK1 are required for both eNAD $(\mathrm{P})^{+}$signaling and SAR (Fig. 5). The above hypothesis is also supported by our previous finding that removal of eNAD $(\mathrm{P})^{+}$by transgenic expression of the human $\mathrm{NAD}(\mathrm{P})^{+}$ hydrolyzing ectoenzyme CD38 partially compromises biological induction of $\mathrm{SAR}^{21}$.

Interestingly, locally applied ${ }^{32} \mathrm{P}-\mathrm{NAD}^{+}$and/or its metabolite (s) moved systemically, although the radioactivity signal detected in the systemic leaves is much weaker than that in the local leaves (Fig. 1e, f). Approximately $10.8 \%$ of the applied radioactivity moved into the systemic leaves in wild-type Arabidopsis plants (Supplementary Fig. 2a), suggesting that only a small fraction of eNAD $(\mathrm{P})^{+}$accumulated in the local leaves could be transported to the systemic leaves. Similarly, only a small fraction $(\sim 7-10 \%)$ of several other putative SAR mobile signals including AzA and G3P is transported from the local to systemic leaves ${ }^{57}$. Thus, eNAD $(\mathrm{P})^{+}$could potentially function as an SAR mobile signal in plants. However, as exogenously added molecules often move systemically 58,59 , further in-depth investigations are required to conclusively determine whether and how endogenous eNAD $(\mathrm{P})+$ moves.

Treatment of various SAR mutants revealed that $\operatorname{eNAD}(\mathrm{P})^{+}$ functions either downstream or independently of the putative mobile signals Pip, NHP, G3P, and AzA in both local and systemic leaves (Fig. 3c and Supplementary Fig. 4a). It has been proposed that Pip, NO, ROS, AzA, and G3P function in a signaling amplification loop and that ROS mediates a systemic signal network in $\mathrm{SAR}^{7,15,16}$. Biochemically, ROS has been shown to oxidize cell membrane, leading to pore formation and membrane disintegration ${ }^{60,61}$. Thus, the ROS produced in the Pip-NO-ROS-AzA-G3P amplification loop may cause reversible or irreversible injuries to the plasma membrane, resulting in leakage of cellular $\mathrm{NAD}(\mathrm{P})^{+}$into the extracellular space to activate its receptor LecRK-VI.2. On the other hand, eNAD $(\mathrm{P})^{+}$-induced defense signaling requires SA (Fig. $3 c$ and Supplementary Fig. 4a), and, conversely, SA induces LecRK-VI.2 gene expression through the coactivator NPR1 (Supplementary Fig. 5c). These results suggest a signaling amplification loop involving SA, NPR1, and LecRK-VI.2. Nevertheless, as NAD $(\mathrm{P})^{+}$-induced expression of $P R 1$, an SA pathway marker gene, is 
not always correlated with $\mathrm{NAD}(\mathrm{P})^{+}$-induced disease resistance (Fig. 3a, b and 5a, b), the relationship between $\operatorname{eNAD}(\mathrm{P})^{+}$and $\mathrm{SA}$ as well as other SAR signal molecules is complicated and warrants further investigation.

LecRK-VI.2 binds both $\mathrm{NAD}^{+}$and $\mathrm{NADP}^{+}$(Fig. 2e-h), indicating that LecRK-VI.2 is a potential receptor for both $\mathrm{NAD}^{+}$ and $\mathrm{NADP}^{+}$. Interestingly, mutations in LecRK-VI.2 did not affect $\mathrm{NAD}^{+}$-induced resistance to Psm in the local leaves ${ }^{22}$, but completely blocked both $\mathrm{NAD}^{+}$- and $\mathrm{NADP}^{+}$-induced resistance in the systemic leaves (Fig. 3b), suggesting that LecRK-VI.2 may be involved in eNAD $(\mathrm{P})^{+}$-triggered SAR signal production in the local leaves and/or perceiving $\operatorname{eNAD}(\mathrm{P})^{+}$and/or other signal molecules in the systemic leaves. Furthermore, while exogenous $\mathrm{NAD}(\mathrm{P})^{+}$-induced systemic PR1 transcription was only slightly reduced in lecrk-VI.2 mutants (Fig. 3a), Psm-induced systemic $P R$ gene expression was almost completely abolished (Fig. $4 \mathrm{a}-\mathrm{c}$ ), suggesting that LecRK-VI.2 may have $\operatorname{eNAD}(\mathrm{P})^{+}$-independent functions. This is not without precedent for PRRs. For instance, the human cell-surface receptors TLR2 (Toll-like receptor 2) and TLR4 recognize a group of chemically different ligands including PAMPs and DAMPs ${ }^{62}$. Further investigation on potential ligands of LecRK-VI.2 would help reveal the activation mechanisms of this important plant immune regulator.

Mutations in LecRK-VI.2 had no effect on basal immunity against bacterial pathogens when the bacteria were inoculated by leaf infiltration ${ }^{25}$, but significantly suppressed biological induction of SAR (Fig. 4). The partial SAR defect in lecrk-VI.2 mutants may be attributed to possible redundancy in $\operatorname{eNAD}(\mathrm{P})^{+}$perception, as the Arabidopsis genome encodes 75 LecRKs (32 G-type, 42 L-type, and 1 C-type) ${ }^{63}$. Indeed, LecRK-VI.2 is not the only receptor for eNAD(P) ${ }^{+}$in Arabidopsis ${ }^{22}$. Nevertheless, $~ 90 \%$ of the transcriptome changes in the systemic leaves were suppressed in the lecrk-VI.2-2 mutant (Fig. 4e, f), indicating that LecRK-VI.2 is a key SAR signaling component responsible for the vast majority of SAR signaling triggered by Psm. In line with this conclusion, overexpression of LecRK-VI.2 has been shown to confer constitutive resistance against bacterial pathogens, which is a phenotype similar to $\mathrm{SAR}^{25}$. As LecRK-VI.2 is a plasma membrane-located transmembrane protein with an extracellular $\mathrm{NAD}(\mathrm{P})^{+}$-binding domain and a cytoplasmic kinase domain (Fig. 2e-h $)^{64,65}$, these results suggest that $\operatorname{eNAD}(\mathrm{P})^{+}$-triggered LecRK-VI.2-mediated outside-in signaling is an integral constituent of the SAR signaling pathway. In support of this hypothesis, the LecRK-VI.2-associating BAK1 and its homolog BKK1, two plasma membrane-located LRR-RKs $s^{50,54,55}$, are also required for SAR (Fig. 5c, d).

BAK1 and BKK1 have been established as crucial co-receptors or adaptors for a number of LRR domain PRRs ${ }^{66}$. The PRRBAK1 immune complex formation is fine-tuned by other regulators. For instance, the malectin-like RLKs FERONIA (FER) and IMPAIRED OOMYCETE SUSCEPTIBILITY1 constitutively associate with both FLS2 and BAK1 to act as scaffolds for ligandinduced FLS2-BAK1 complex formation ${ }^{67,68}$. FER is a receptor for several Arabidopsis RAPID ALKALINIZATION FACTORs (RALFs) ${ }^{68,69}$. The constitutive association between BAK1 and FER can be strongly enhanced upon treatment with flg22, whereas binding of RALF23 to FER inhibits flg22-induced complex formation between FLS2 and BAK1 ${ }^{68}$. LecRK-VI.2 also constitutively associates with FLS2 and BAK1 ${ }^{70}$ (Fig. 6), but is dispensable for flg22-induced FLS2-BAK1 complex formation, suggesting a distinct mechanism underlying the function of LecRK-VI.2 in PTI. As a potential eNAD $(\mathrm{P})^{+}$receptor, binding of $\operatorname{eNAD}(\mathrm{P})^{+}$may enhance its function in the FLS2-BAK1 immune complex. Indeed, exogenous $\mathrm{NAD}^{+}$induces expression of the PTI marker genes WRKY53 and FRK1 as well as production of $\operatorname{ROS}^{20,22}$
The interplay between $\operatorname{eNAD}(\mathrm{P})^{+}$and flg22 (and other PAMPs) signaling is complex and deserves further attention. Recognition of flg22 by FLS2 results in PTI responses including ROS burst, which could potentially damage the plasma membrane, contributing to accumulation of eNAD $(\mathrm{P})^{+}$. eNAD $(\mathrm{P})^{+}$in turn could potentiate flg22 signaling through the LecRK-VI.2FLS2 complex. Indeed, flg22-induced MPK3/6 activation, callose deposition, and stomatal closure are inhibited in lecrk-VI.2mutant plants ${ }^{25}$, though the contribution of $\operatorname{eNAD}(\mathrm{P})^{+}$in this process remains to be determined. On the other hand, the potential roles of $\mathrm{eNAD}(\mathrm{P})^{+}$in PAMP signaling and SAR are clearly distinct. First, only BAK1 and BKK1, but not FLS2, are required for SAR (Fig. $5 \mathrm{c}, \mathrm{d}$ ), indicating that the LecRK-VI.2BAK1 complex, but not the LecRK-VI.2-FLS2 complex, has a major role in SAR. In agreement with this idea, flg22-induced systemic immunity is compromised in the lecrk-VI.2 mutants, whereas flg22-induced local apoplastic resistance is not significantly affected by the mutations (Supplementary Fig. 12d, e). Furthermore, the BAK1-GFP fusion is not functional in PTI responses ${ }^{56}$, but is active in $\mathrm{NAD}(\mathrm{P})^{+}$signaling and $\mathrm{SAR}$ (Fig. 7d-f), indicating that the LecRK-VI.2-BAK1 complexmediated $\mathrm{eNAD}(\mathrm{P})^{+}$signaling is likely independent or downstream of flg22 signaling.

The kinase activities of both LecRK-VI.2 and BAK1 are essential to their function in $\mathrm{eNADP}^{+}$signaling and SAR (Fig. 7), suggesting that binding of eNAD $(\mathrm{P})^{+}$to LecRK-VI. 2 may trigger transphosphorylation between LecRK-VI.2 and BAK1, which in turn may phosphorylate downstream target(s). A potential target is the serine/threonine kinase SNF1-RELATED PROTEIN KINASE2.8 (SnRK2.8), which has been shown to function in SAR via phosphorylating NPR1 $1^{71}$. NPR1 is a master transcription coactivator in plants and nuclear localization is required for its function in plant immunity ${ }^{33}$. In the systemic leaves, SAR activation-induced redox changes switch NPR1 from an oligomer to monomers and SnRK2.8 phosphorylates monomeric NPR1 at Ser-589 and Thr-373 to facilitate its nuclear import, which is a critical step in SAR induction ${ }^{71}$.

Induction of SAR comprises four stages: signal generation, signal translocation, signal perception, and SAR execution. Among the four stages, signal perception in the systemic leaves is the least understood 3,24 . In this study, we uncovered a putative SAR mobile signal eNAD $(\mathrm{P})^{+}$and its potential receptor LecRKVI.2 and demonstrate that the LecRK-VI.2/BAK1 complex has a pivotal role in SAR. Identification of the precise relationship between eNAD $(\mathrm{P})^{+}$and other SAR signal molecules as well as the downstream targets of the LecRK-VI.2/BAK1 complex will shed further light on the SAR signaling process.

\section{Methods}

Arabidopsis growth. Arabidopsis thaliana seeds were sown on autoclaved soil (Sunshine MVP; Sun Gro Horticulture, Agawam, MA, USA) and cold-treated at $4{ }^{\circ} \mathrm{C}$ for 3 days. After germination, seedlings were grown at $22-24^{\circ} \mathrm{C}$ under a 16-hr-light/8-hr-dark regime for 2 weeks. Seedlings were then transplanted individually into pots containing the autoclaved soil. Four-week-old plants were used for $\mathrm{NAD}(\mathrm{P})^{+}$treatment and Psm inoculation.

Pseudomonas culture. Pseudomonas syringae pv. maculicola ES4326 (Psm) was grown at $28^{\circ} \mathrm{C}$ in King's B medium containing $50 \mu \mathrm{g} \mathrm{mL}^{-1}$ streptomycin under shaking at $220 \mathrm{rpm}$. Bacteria in overnight log-phase cultures were precipitated by centrifugation at $500 \times g$ for $5 \mathrm{~min}$, re-suspended in $10 \mathrm{mM} \mathrm{MgCl}_{2}$, and diluted to different final $\mathrm{OD}_{600}$ levels for leaf infiltration experiments.

NAD(P) leakage. Three fully expanded leaves on each 4-week-old soil-grown Arabidopsis plant were infiltrated from the abaxial side with $10 \mathrm{~mm} \mathrm{MgCl}_{2}$ (mock) or a Psm suspension $\left(\mathrm{OD}_{600}=0.002\right)$. Ten min after the treatment, 30 leaf disks ( $\sim 7 \mathrm{~mm}$ in diameter) for each treatment were removed and washed twice for a total of $50 \mathrm{~min}$. Sets of 10 leaf disks each were then placed in $5 \mathrm{~mL}$ fresh water in a test tube. $\mathrm{NAD}(\mathrm{P})$ concentrations in the water were measured over time following an 
enzymatic cycling assay protocol. One hundred $\mu \mathrm{L}$ of the water surrounding the leaf disks was added into a $1.5 \mathrm{~mL}$ microcentrifuge tube containing $0.1 \mathrm{~mL}$ Bicine$\mathrm{NaOH}$ buffer (1.0 M, pH 8.0), followed by addition of $0.1 \mathrm{~mL}$ each of EDTA (disodium salt, $40 \mathrm{mM}$ ), 3-(4,5-dimethylthiazolyl-2)-2,5-diphenyltetrazolium bromide (MTT, $4.2 \mathrm{mM}$ ), phenazine ethosulfate (PES, $16.6 \mathrm{mM}$ ), and ethanol $(5.0 \mathrm{M})$ for the determination of NAD or $0.05 \mathrm{~mL}$ of glucose-6-phosphate (G6P, $50 \mathrm{~mm}$ ) for the determination of NADP. After adjusting the total volume to $1 \mathrm{~mL}$ by adding $\mathrm{H}_{2} \mathrm{O}$, the microcentrifuge tube was kept at $37^{\circ} \mathrm{C}$ for $5 \mathrm{~min}$. The reaction was started by adding $0.02 \mathrm{~mL}$ of alcohol dehydrogenase ( 500 units $\mathrm{mL}^{-1}$, for NAD) or G6P dehydrogenase ( 35 units $\mathrm{mL}^{-1}$, for NADP). After incubated at $37^{\circ} \mathrm{C}$ for $10 \mathrm{~min}$, the reaction mixture was transferred to a microcuvette and the absorbance at $570 \mathrm{~nm}$ was measured with a Beckman Du640 spectrophotometer (Beckman).

Plant treatment with NAD $^{+}$and NADP ${ }^{+} . \beta$-Nicotinamide adenine dinucleotide sodium salt $\left(\mathrm{NAD}^{+}-\mathrm{Na}\right.$; Sigma-Aldrich) and $\beta-\mathrm{NAD}^{+}$phosphate sodium $\left(\mathrm{NADP}^{+}-\mathrm{Na}\right.$; Sigma-Aldrich) were dissolved in water, and the $\mathrm{pH}$ of the resulting solutions was adjusted to $\sim 6.0$ using $0.1 \mathrm{M} \mathrm{NaOH}$. The solution $\left(0.2 \mathrm{mM} \mathrm{NAD}^{+}\right.$or $0.4 \mathrm{~mm} \mathrm{NADP}^{+}$) was infiltrated from the abaxial side into Arabidopsis leaves of 4 week-old soil-grown plants using a 1-mL needleless syringe. Distilled water was used as the negative control. The infiltration was conducted between 10 and 11 $\mathrm{AM}$. For $\mathrm{NAD}(\mathrm{P})^{+}$-induced defense gene expression, the infiltrated leaf tissues were collected $20 \mathrm{hr}$ after the treatment for RNA analysis. For $\mathrm{NAD}(\mathrm{P})^{+}$-induced Psm resistance, the infiltrated leaves were inoculated with Psm $5 \mathrm{hr}$ after the NAD $(\mathrm{P})^{+}$treatment as described below ("assessment of plant resistance to Psm"). For SAR induction, three lower leaves on each Arabidopsis plant were infiltrated with $\mathrm{H}_{2} \mathrm{O}$ (mock), $0.4 \mathrm{~mm} \mathrm{NAD}{ }^{+}$, or $0.8 \mathrm{~mm} \mathrm{NADP}{ }^{+}$every $12 \mathrm{hr}$ for a total of four times. The first infiltration was performed at around $9 \mathrm{PM}$. About $5 \mathrm{hr}$ after the last infiltration, two systemic (upper untreated) leaves were either collected for defense gene analysis or challenge-inoculated with Psm as described below ("assessment of plant resistance to Psm").

Biological induction of SAR. Three lower leaves on each 4-week-old soil-grown Arabidopsis plant were infiltrated from the abaxial side with $10 \mathrm{mM} \mathrm{MgCl}_{2}$ (mock) or a $P s m$ suspension $\left(\mathrm{OD}_{600}=0.002\right)$. The SAR activation treatment was conducted between 10 and $11 \mathrm{AM}$. Two days later, two systemic leaves were either collected for defense gene analysis or challenge-inoculated with Psm as described below ("assessment of plant resistance to Psm").

Assessment of plant resistance to Psm. To assess Psm resistance in the NAD $(\mathrm{P})^{+}$-treated leaves or the systemic leaves, a Psm suspension $\left(\mathrm{OD}_{600}=0.001\right)$ was infiltrated from the abaxial side into the target leaves using a 1-mL needleless syringe. A total of 12 plants were used per genotype/treatment. Two and a half to three days later, eight leaves per genotype/treatment from eight plants (one leaf from each plant) were collected to examine the growth of the pathogen. A leaf disk ( $\sim 7 \mathrm{~mm}$ in diameter) was removed from each leaf using a hole punch and the leaf disk was placed into $500 \mu \mathrm{L}$ of $10 \mathrm{mM} \mathrm{MgCl}_{2}$ in a $2-\mathrm{mL}$ microcentrifuge tube and ground forcefully using a plastic pestle. Twenty-fold serial dilutions of the homogenate were plated on trypticase soy agar (BD) plates supplemented with $50 \mu \mathrm{g} / \mathrm{mL}$ streptomycin to determine bacterial concentrations. Bacterial growth rates were expressed as colony-forming units (cfu) per leaf disk area. All experiments depicted in the figures were repeated at least three times with similar results.

RNA analysis. For reverse transcription (RT), total RNA was treated with DNase I (ThermoFisher Scientific) at $37^{\circ} \mathrm{C}$ for $30 \mathrm{~min}$. After inactivation of the DNase, RT was performed using SUPERSCRIPT First-strand Synthesis System (ThermoFisher Scientific) and $2 \mu \mathrm{g}$ of the DNase-treated RNA in a $20 \mu \mathrm{L}$ reaction. Quantitative PCR was performed using SYBR Green protocol (Applied Biosystems) with $1 \mu \mathrm{M}$ primers and $0.2 \mu \mathrm{L}$ aliquot of RT product in a total of $12.5 \mu \mathrm{L}$ per reaction. Reactions were run and analyzed on a MX3000P real-time PCR machine (Stratagene) according to the manufacturer's instructions. A standard curve was made by determining the threshold cycle $(\mathrm{Ct})$ values for a dilution series of the RT reaction product for each primer pair. For each reaction, the $\mathrm{Ct}$ was determined by setting the threshold within the logarithmic amplification phase. The relative quantity of a gene is expressed in relation to UBIQUITIN5 (UBQ5) using the formula $2^{\wedge}$ $\left(\mathrm{Ct}^{U B Q 5}{ }_{-} \mathrm{Ct}^{G E N E}\right)$, where 2 represents perfect PCR efficiency. All experiments described in the figures were repeated at least three times with similar results.

NAD ${ }^{+}$movement assay. Three lower leaves on a 4 -week-old soil-grown Arabidopsis plant or two lower leaves on a 5-week-old soil-grown $N$. benthamiana plant were infiltrated from the abaxial side with a water solution of $1 \mathrm{~mm}$ unlabeled $\mathrm{NAD}^{+}$plus $6.25 \mathrm{~nm}^{32} \mathrm{P}-\mathrm{NAD}^{+}$(specific activity $800 \mathrm{Ci} / \mathrm{mmol}$; PerkinElmer, USA). The treated plants were incubated at $22-24^{\circ} \mathrm{C}$ under a 16 -hr-light/8-hr-dark regime for $24 \mathrm{hr}$. The infiltrated leaves and two systemic leaves from each plant were collected, wrapped with plastic waterproofing membrane, and exposed to Xray film for $24 \mathrm{hr}$ at $-80^{\circ} \mathrm{C}$. The $\mathrm{X}$-ray film was then developed to visualize the radioactivity in the leaves.
Protein purification. For purification of MBP, MBP-eLecRK-VI.2, and MBPeDORN1, a single colony of BL21(DE3) carrying the corresponding plasmid was cultured overnight at $37^{\circ} \mathrm{C}$ in $5 \mathrm{~mL}$ Lysogeny broth (LB) with $50 \mu \mathrm{g} / \mathrm{mL}$ ampicillin. One $\mathrm{mL}$ of the seed culture was added to $500 \mathrm{~mL}$ fresh LB medium with $50 \mu \mathrm{g} / \mathrm{mL}$ ampicillin and cultured at $37^{\circ} \mathrm{C}$ with shaking to an $\mathrm{OD}_{600}$ of 0.4 . Isopropyl $\beta$-D-1thiogalactopyranoside was added to a final concentration of $0.3 \mathrm{~mm}$ and the culture was allowed to grow for another $16-18 \mathrm{hr}$ at $18^{\circ} \mathrm{C}$ before the cells were harvested for protein extraction. MBP-fusion proteins were purified with amylose resin according to the protocol supplied by the manufacturer (New England BioLabs).

NAD+-binding assays. Amylose resin beads with the bound proteins were resuspended in binding buffer (10 mM HEPES, pH 7.5, $5 \mathrm{~mm} \mathrm{MgCl}_{2}$ ) and aliquoted in $86 \mu \mathrm{L}$ portions for individual binding reactions. For total binding assay, $10 \mu \mathrm{L}$ binding buffer and $4 \mu \mathrm{L}^{32} \mathrm{P}-\mathrm{NAD}^{+}(6.25 \mu \mathrm{M})$ were added, resulting in $250 \mathrm{nM}^{32} \mathrm{P}-$ $\mathrm{NAD}^{+}$in the final $100 \mu \mathrm{L}$ reaction mixture. For nonspecific binding, $10 \mu \mathrm{L}$ of $2.5 \mathrm{~mm}$ unlabeled $\mathrm{NAD}^{+}$and $4 \mu \mathrm{L}^{32} \mathrm{P}$-labeled $\mathrm{NAD}^{+}$were added, resulting in $250 \mu \mathrm{m}$ unlabeled $\mathrm{NAD}^{+}$and $250 \mathrm{~nm}^{32} \mathrm{P}^{-\mathrm{NAD}^{+}}$in the final $100 \mu \mathrm{L}$ reaction mixture. The mixtures were incubated for $30 \mathrm{~min}$ at room temperature with gentle mixing every $5 \mathrm{~min}$. The beads containing the binding reactions were then precipitated by centrifugation at $500 \times g$ for $5 \mathrm{~min}$, washed three times with the binding buffer, re-suspended in $10 \mathrm{~mL}$ ScintiVerse BD Cocktail (ThermoFisher Scientific) per sample, and carefully transferred into scintillation vials. The vials were placed in a Beckman Coulter LS6500 Multi-Purpose Scintillation Counter (Beckman) and bound ${ }^{32} \mathrm{P}-\mathrm{NAD}^{+}$was quantified by scintillation counting. Specific $\mathrm{NAD}^{+}$binding was calculated by subtracting the nonspecific binding from the total binding. For saturation binding assay, amylose resin beads with the bound proteins were incubated with different concentrations $(50,200,500,1000,1500$, and $2000 \mathrm{nM}$ ) of ${ }^{32} \mathrm{P}_{-N A D}{ }^{+}$in the absence (for total binding) or presence (for nonspecific binding) of additional 1000-fold unlabeled $\mathrm{NAD}^{+}$in the binding buffer. The dissociation constant $(K \mathrm{~d})$ was calculated by one site specific binding saturation model using GraphPad Prism 7 (GraphPad Software, La Jolla, CA, USA). For competitive binding assay, amylose resin beads with the bound proteins were incubated with $250 \mathrm{~nm}$ of ${ }^{32} \mathrm{P}$-labeled $\mathrm{NAD}^{+}$in the presence of different concentrations ( $100 \mathrm{nM}, 1 \mu \mathrm{M}, 10 \mu \mathrm{M}, 100 \mu \mathrm{M}$, and $1 \mathrm{~mm}$ ) of unlabeled nucleotides $\left(\mathrm{NAD}^{+}, \mathrm{NADP}^{+}\right.$, and $\left.\mathrm{ATP}\right)$ in the binding buffer. The $50 \%$ inhibition concentration $\left(\mathrm{IC}_{50}\right.$ ) values were calculated by importing the data points into GraphPad Prism 7 using the one site Fit $\log \mathrm{IC}_{50}$ competition model.

For microsome-based binding assays, Arabidopsis plants were grown under a 15-hr-light/9-hr-dark regime for about 6 weeks. Rosette leaf tissues were homogenized with a mortar and pestle in $1 \mathrm{~mL} / 1$ gram chilled membrane extraction buffer (20 mM Tris- $\mathrm{HCl}, \mathrm{pH} 7.5,250 \mathrm{~mm}$ mannitol, $5 \mathrm{~mm} \mathrm{MgCl}, 0.1 \mathrm{~mm}$ $\mathrm{CaCl}_{2}$, and protease inhibitors). Homogenates were filtered through two layers of Miracloth and centrifuged at $10,000 \times g$ for $10 \mathrm{~min}$ at $4^{\circ} \mathrm{C}$. The supernatant was centrifuged at $100,000 \times g$ for $1 \mathrm{hr}$ at $4^{\circ} \mathrm{C}$ to pellet microsomes. The microsomal pellet was re-suspended at a protein concentration of $2 \mathrm{mg} / \mathrm{mL}$ in binding buffer (10 mM MES-KOH, pH 5.7, $5 \mathrm{mM} \mathrm{MgCl}_{2}, 0.25 \mathrm{mM} \mathrm{CaCl}_{2}, 0.25 \mathrm{M}$ mannitol, and protease inhibitors) and aliquoted in $10 \mu \mathrm{L}$ portions for individual binding reactions. For total binding assay, $4 \mu \mathrm{L}$ binding buffer and $1 \mu \mathrm{L}^{32} \mathrm{P}-\mathrm{NAD}^{+}$were added, resulting in $\sim 420 \mathrm{nM}^{32} \mathrm{P}-\mathrm{NAD}^{+}$in the final $15 \mu \mathrm{L}$ reaction mixture. For competitive binding assay, the microsomes were incubated with $420 \mathrm{nM}^{32} \mathrm{P}-\mathrm{NAD}^{+}$ in the presence of $420 \mu \mathrm{m}$ unlabeled $\mathrm{NAD}^{+}$or $\mathrm{NADP}^{+}$in the binding buffer. The binding reactions were incubated for $30 \mathrm{~min}$ at room temperature with gentle mixing every $5 \mathrm{~min}$. The bound and free ${ }^{32} \mathrm{P}-\mathrm{NAD}^{+}$were separated by filtering the mixture through a glass-fiber filter (GE Healthcare) and washing with $10 \mathrm{~mL}$ icecold binding buffer, and were quantified by scintillation counting.

Microarray analysis. Three lower leaves on each four-week-old soil-grown plant were infiltrated with either $10 \mathrm{~mm} \mathrm{MgCl}_{2}$ (-SAR) or Psm $\left(\mathrm{OD}_{600}=0.002\right)(+\mathrm{SAR})$. Two days later, the systemic leaves were collected for total RNA extraction. Total RNA samples were subjected to microarray analysis using the Affymetrix microarray platform, which was performed at Interdisciplinary Center for Biotechnology Research Gene Expression and Genotyping Core at The University of Florida. RNA concentration was determined on a NanoDrop Spectrophotometer (ThermoFisher Scientific) and sample quality was assessed using the Agilent 2100 Bioanalyzer (Agilent Technologies). All microarray sample preparation used the GeneChip 3' IVT Plus Express kit (ThermoFisher Scientific), and reactions were done following the manufacturer's protocols. In brief, cDNA was synthesized from $500 \mathrm{ng}$ of total RNA and used as template for in vitro transcription during which a biotinmodified nucleotide was incorporated. The biotin-labeled aRNA (amplified RNA) was then purified and fragmented. Eleven $\mu \mathrm{g}$ of biotin-labeled aRNAs were hybridized with rotation at $45^{\circ} \mathrm{C}$ for $16 \mathrm{hr}$ to the GeneChip Arabidopsis Genome ATH1 Array (ThermoFisher Scientific). The arrays were washed and stained with the reagents supplied in GeneChip Hybridization Wash and Stain kit (ThermoFisher Scientific) on an Affymetrix Fluidics Station 450, and scanned with a GeneChip 7 G Scanner (ThermoFisher Scientific).

The microarray data were pre-processed and normalized using the affy package $^{72}$. The Robust Multichip Analysis approach was applied for the normalization. After normalization, the empirical Bayes moderated $t$ statistics, which is implemented in the limma Bioconductor package ${ }^{73}$, was performed for differential expression detection. In each comparison, a $p$ value and fold change 
were computed for each gene locus. The gene expression fold changes were computed based on the normalized log-transformed signal intensity data. To control false discovery rate and correct multiple hypothesis testing, a $q$ value was calculated and used to assess the significance of each test using Benjamini and Hochberg's approach ${ }^{74}$. Genes with an absolute fold change $\geq 2$ and a $q$ value $\leq$ 0.05 were considered as significantly induced or suppressed and were then further explored to obtain overlapped genes among genotypes. The venn function implement in limma package was applied to compute classification counts and draw a venn diagram.

Plasmid construction and plant transformation. For expression of the MBPeLecRK-VI.2 fusion protein in E. coli, the DNA fragment encoding the extracellular domain (AAs 23-310) of LecRK-VI.2 was amplified using the primers XbaIeLecRK-VI.2 F and HindIII-eLecRK-VI.2 R (All primers are listed Supplementary Table 1). The PCR products were digested with XbaI and HindIII and cloned into the XbaI/HindIII site of pMAL-p2X, generating pMAL-p2X-eLecRK-VI.2. The pMAL-p2X-eDORN1 plasmid has previously been described ${ }^{22}$. For expression of the MBP-LecRK-VI.2KD (AAs 331-682) and GST-BAK1KD (AAs 250-615) fusion proteins in E. coli, DNA fragments encoding the KDs of LecRK-VI.2 and BAK1 were amplified using primers BglII-LecRK-VI.2KDF/XhoI-LecRK-VI.2KDR and EcoRI-BAK1KDF/SalI-BAK1KDR and cloned into the BamHI/SalI site of pMAL-p2X and the EcoRI/SalI site of pGEX-4T-1, generating pMAL-p2X-LecRKVI.2KD and pGEX-4T-BAK1KD, respectively. For transient expression in $N$. benthamiana, the coding regions of LecRK-VI.2 and BAK1 were amplified using primers XbaI-LecRK-VI.2 F/XhoI-lecRK-VI.2-noStopR and SacI-BAK1F/SalIBAK1-noStopR and cloned into the XbaI/SalI site of pCAMBIA1300S-FLAG and the SacI/SalI site of pCAMBIA1300S-GFP, resulting in pCAMBIA1300S-LecRKVI.2-FLAG and pCAMBIA1300S-BAK1-GFP, respectively. For generation of transgenic Arabidopsis plants expressing LecRK-VI.2-HA, the DNA fragment containing the LecRK-VI.2 promoter and coding region was amplified using primers XbaI-LecRK-VI.2PF and BglII-3×HA-lecRK-VI.2 R and cloned into the XbaI/ BamHI site of pCB302, resulting in pCB302-LecRK-VI.2:LecRK-VI.2-HA. Sitedirected mutagenesis of Asp494 of LecRK-VI.2 and Lys317 of BAK1 was performed in pCB302-LecRK-VI.2:LecRK-VI.2-HA and pCAMBIA1300S-BAK1-GFP, respectively, using primers listed in Supplementary Table 1 . The presence of the expected mutations in the resulting constructs was verified by DNA sequencing. The plasmids pCAMBIA1300S-LecRK-VI.2-FLAG, pCAMBIA1300S-BAK1-GFP pCB302-LecRK-VI.2:LecRK-VI.2-HA, pCB302-LecRK-VI.2:LecRK-VI.2(D494N)$\mathrm{HA}$, and pCAMBIA1300S-BAK1(K317E)-GFP were introduced into the Agrobacterium strain GV3101(pMP90) and pMAL-p2X, pMAL-p2X-eLecRK-VI.2, pMAL-p2X-eDORN1, pMAL-p2X-LecRK-VI.2KD, and pGEX-4T-BAK1KD were introduced into the E. coli strain BL21(DE3) by electroporation.

For transient expression in N. benthamiana, Agrobacteria carrying pCAMBIA1300S-LecRK-VI.2-FLAG, pCAMBIA1300S-BAK1-GFP were suspended in an induction buffer (10 mM MES-KOH, pH 5.6, $10 \mathrm{~mm} \mathrm{MgCl}_{2}$ and $100 \mu \mathrm{M}$ acetosyringone) to an $\mathrm{OD}_{600}$ of 0.4 , pre-induced for 2 to $3 \mathrm{~h}$ at $28^{\circ} \mathrm{C}$, mixed in a 1:1 ratio before infiltration, and then infiltrated from the abaxial side into $N$. benthamiana leaves using a $1-\mathrm{mL}$ needleless syringe. Two to 3 days later, the leaves infiltrated with the Agrobacteria were used for co-immunoprecipitation analysis.

Pull-down and co-immunoprecipitation assays. One microgram MBP or MBPLecRK-VI.2KD was incubated with $1 \mu \mathrm{g}$ GST-BAK1KD in a binding buffer $(20 \mathrm{~mm}$ Tris- $\mathrm{HCl}, 200 \mathrm{~mm} \mathrm{NaCl}, 1 \mathrm{~mm}$ EDTA, pH 7.4) under agitation at $4{ }^{\circ} \mathrm{C}$. After $2 \mathrm{hr}$, $50 \mu \mathrm{L}$ amylose resin beads (New England BioLabs, E8021S) were added, and the incubation continued for another $2 \mathrm{hr}$. The beads were then washed five times with the washing buffer ( $20 \mathrm{~mm}$ Tris- $\mathrm{HCl}, 200 \mathrm{~mm} \mathrm{NaCl}, 1 \mathrm{~mm}$ EDTA, 0.6\% Triton X$100, \mathrm{pH}$ 7.4). Input and pulled down proteins were resolved by $8 \%$ sodium dodecyl sulphate-polyacrylamide gel electrophoresis (SDS-PAGE) and detected by immunoblotting using anti-MBP (New England BioLabs, E8032S, dilution 1:10,000) and anti-GST (Cell Signaling, 2625 S, dilution 1:1000) antibodies. Co-

immunoprecipitation assay was performed as described by Roux et al. ${ }^{47}$. N. benthamiana or Arabidopsis leaves were ground in liquid nitrogen and extraction buffer ( $50 \mathrm{~mm}$ Tris- $\mathrm{HCl}, \mathrm{pH}$ 7.5, $150 \mathrm{~mm} \mathrm{NaCl}, 10 \%$ glycerol, $10 \mathrm{~mm}$ DTT, $10 \mathrm{~mm}$ EDTA, $1 \mathrm{~mm} \mathrm{NaF}, 1 \mathrm{~mm} \mathrm{Na} \mathrm{MoO}_{4}, 1 \%$ [w/v] polyvinylpyrrolidone, $1 \%$ [v/v] IGEPAL CA-630, and $1 \%$ [v/v] protease inhibitor cocktail) was added at $2 \mathrm{~mL} / \mathrm{g}$ tissue powder. Samples were clarified by centrifugation at $16,000 \times g$ at $4{ }^{\circ} \mathrm{C}$ for 20 min. For N. benthamiana, the supernatant was incubated with anti-FLAG M2 affinity agarose gel (Sigma-Aldrich, A2220) at $4{ }^{\circ} \mathrm{C}$ for $4 \mathrm{hr}$. For Arabidopsis, the supernatant was incubated with monoclonal anti-GFP antibody (Santa Cruz Biotechnology, sc-9996) overnight at $4{ }^{\circ} \mathrm{C}$ followed by precipitation with protein $\mathrm{G}$ plus agarose (Santa Cruz Biotechnology) for $4 \mathrm{hr}$. After washing four times with the extraction buffer, proteins were eluted by boiling in $40 \mu \mathrm{L}$ of $2 \times$ Laemmli sample buffer for $10 \mathrm{~min}$. The eluates were separated on $8 \%$ SDS-PAGE, transferred onto nitrocellulose membranes (Maine Manufacturing, Gloucester, MA, USA). For N. benthamiana, the membranes were probed with monoclonal anti-FLAG (SigmaAldrich, F1804, dilution 1:5000) and polyclonal anti-GFP (Santa Cruz Biotechnology, sc-8334, dilution $1: 1000$ ) antibodies to detect immunoprecipitated LecRK-VI.2-FLAG and co-immunoprecipitated BAK1-GFP, respectively. For Arabidopsis, the membranes were probed with polyclonal anti-GFP and monoclonal anti-HA (Santa Cruz Biotechnology, sc-7392, dilution 1:1000) antibodies to detect immunoprecipitated BAK1-GFP protein and co-immunoprecipitated LecRK-VI.2-HA, respectively.

Quantification and statistical analysis. Statistical analyses were performed using the data analysis tools (Student's $t$ test) in Microsoft Excel of Microsoft Office 2011 for Macintosh as well as the one-way ANOVA and the two-way ANOVA in Prism 7. Unless indicated otherwise, all experiments were repeated at least three times with similar trends.

Reporting summary. Further information on research design is available in the Nature Research Reporting Summary linked to this article.

\section{Data availability}

The authors declare that all data supporting the findings of this study are available within the manuscript and its supplementary files or are available from the corresponding author upon request. The source data underlying Figs. 1-7 and Supplementary Figs. 1-12 are provided as a Source Data file. Microarray data generated as part of this study has been deposited in the Gene Expression Omnibus repository under accession code GSE121886.

Received: 20 November 2018; Accepted: 1 October 2019; Published online: 22 October 2019

\section{References}

1. Jones, J. D. \& Dangl, J. L. The plant immune system. Nature 444, 323-329 (2006).

2. Choi, H. W. \& Klessig, D. F. DAMPs, MAMPs, and NAMPs in plant innate immunity. BMC Plant Biol. 16, 232 (2016).

3. Fu, Z. Q. \& Dong, X. Systemic acquired resistance: turning local infection into global defense. Annu Rev. Plant Biol. 64, 839-863 (2013).

4. Maldonado, A. M., Doerner, P., Dixon, R. A., Lamb, C. J. \& Cameron, R. K. A putative lipid transfer protein involved in systemic resistance signalling in Arabidopsis. Nature 419, 399-403 (2002).

5. Shulaev, V., Silverman, P. \& Raskin, I. Airborne signaling by methyl salicylate in plant pathogen resistance. Nature 385, 718-721 (1997).

6. Park, S. W., Kaimoyo, E., Kumar, D., Mosher, S. \& Klessig, D. F. Methyl salicylate is a critical mobile signal for plant systemic acquired resistance. Science 318, 113-116 (2007).

7. Wang, C. et al. Pipecolic acid confers systemic immunity by regulating free radicals. Sci. Adv. 4, eaar4509 (2018).

8. Chaturvedi, R. et al. An abietane diterpenoid is a potent activator of systemic acquired resistance. Plant J. 71, 161-172 (2012).

9. Jung, H. W., Tschaplinski, T. J., Wang, L., Glazebrook, J. \& Greenberg, J. T. Priming in systemic plant immunity. Science 324, 89-91 (2009).

10. Chanda, B. et al. Glycerol-3-phosphate is a critical mobile inducer of systemic immunity in plants. Nat. Genet 43, 421-427 (2011).

11. Navarova, H., Bernsdorff, F., Doring, A. C. \& Zeier, J. Pipecolic acid, an endogenous mediator of defense amplification and priming, is a critical regulator of inducible plant immunity. Plant Cell 24, 5123-5141 (2012).

12. Chen, Y. C. et al. N-hydroxy-pipecolic acid is a mobile metabolite that induces systemic disease resistance in Arabidopsis. Proc. Natl. Acad. Sci. USA 115, E4920-E4929 (2018).

13. Hartmann, M. et al. Flavin monooxygenase-generated n-hydroxypipecolic acid is a critical element of plant systemic immunity. Cell 173, 456-469 (2018).

14. Riedlmeier, M. et al. Monoterpenes support systemic acquired resistance within and between plants. Plant Cell 29, 1440-1459 (2017).

15. Alvarez, M. E. et al. Reactive oxygen intermediates mediate a systemic signal network in the establishment of plant immunity. Cell 92, 773-784 (1998).

16. Wang, C. et al. Free radicals mediate systemic acquired resistance. Cell Rep. 7, 348-355 (2014)

17. Berger, F., Ramirez-Hernandez, M. H. \& Ziegler, M. The new life of a centenarian: signalling functions of $\mathrm{NAD}(\mathrm{P})$. Trends Biochem. Sci. 29, 111-118 (2004).

18. Billington, R. A. et al. Emerging functions of extracellular pyridine nucleotides. Mol. Med. 12, 324-327 (2006).

19. Zhang, X. \& Mou, Z. Extracellular pyridine nucleotides induce $P R$ gene expression and disease resistance in Arabidopsis. Plant J. 57, 302-312 (2009).

20. Petriacq, P., Ton, J., Patrit, O., Tcherkez, G. \& Gakiere, B. NAD acts as an integral regulator of multiple defense layers. Plant Physiol. 172, 1465-1479 (2016).

21. Zhang, X. \& Mou, Z. Expression of the human NAD(P)-metabolizing ectoenzyme CD38 compromises systemic acquired resistance in Arabidopsis. Mol. Plant-Microbe Interact. 25, 1209-1218 (2012). 
22. Wang, C. et al. A lectin receptor kinase as a potential sensor for extracellular nicotinamide adenine dinucleotide in Arabidopsis thaliana. eLife 6, e25474 (2017).

23. Uknes, S. et al. Acquired resistance in Arabidopsis. Plant Cell 4, 645-656 (1992).

24. Adam, A. L., Nagy, Z. A., Katay, G., Mergenthaler, E. \& Viczian, O. Signals of systemic immunity in plants: progress and open questions. Int J. Mol. Sci. 19, 1146 (2018).

25. Singh, P. et al. The lectin receptor kinase-VI.2 is required for priming and positively regulates Arabidopsis pattern-triggered immunity. Plant Cell 24, 1256-1270 (2012).

26. Choi, J. et al. Identification of a plant receptor for extracellular ATP. Science 343, 290-294 (2014).

27. McConn, M., Hugly, S., Browse, J. \& Somerville, C. A mutation at the fad8 locus of Arabidopsis identifies a second chloroplast [omega]-3 desaturase. Plant Physiol. 106, 1609-1614 (1994).

28. Wildermuth, M. C., Dewdney, J., Wu, G. \& Ausubel, F. M. Isochorismate synthase is required to synthesize salicylic acid for plant defence. Nature 414, 562-565 (2001).

29. Nawrath, C., Heck, S., Parinthawong, N. \& Métraux, J.-P. EDS5, an essential component of salicylic acid-dependent signaling for disease resistance in Arabidopsis, is a member of the MATE transporter family. Plant Cell $\mathbf{1 4}$ 275-286 (2002).

30. Bartsch, M. et al. Salicylic acid-independent ENHANCED DISEASE SUSCEPTIBILITY1 signaling in Arabidopsis immunity and cell death is regulated by the monooxygenase FMO1 and the Nudix hydrolase NUDT7. Plant Cell 18, 1038-1051 (2006).

31. Jirage, D. et al. Arabidopsis thaliana PAD4 encodes a lipase-like gene that is important for salicylic acid signaling. Proc. Natl. Acad. Sci. USA 96, 13583-13588 (1999).

32. Century, K. S. et al. NDR1, a pathogen-induced component required for Arabidopsis disease resistance. Science 278, 1963-1965 (1997).

33. Cao, H., Glazebrook, J., Clark, J. D., Volko, S. \& Dong, X. The Arabidopsis NPR1 gene that controls systemic acquired resistance encodes a novel protein containing ankyrin repeats. Cell 88, 57-63 (1997).

34. Song, J. T., Lu, H., McDowell, J. M. \& Greenberg, J. T. A key role for ALD1 in activation of local and systemic defenses in Arabidopsis. Plant J. 40, 200-212 (2004).

35. Mishina, T. E. \& Zeier, J. The Arabidopsis flavin-dependent monooxygenase FMO1 is an essential component of biologically induced systemic acquired resistance. Plant Physiol. 141, 1666-1675 (2006).

36. Lu, M., Tang, X. \& Zhou, J. M. Arabidopsis NHO1 is required for general resistance against Pseudomonas bacteria. Plant Cell 13, 437-447 (2001).

37. Yamaguchi, Y., Pearce, G. \& Ryan, C. A. The cell surface leucine-rich repeat receptor for AtPep1, an endogenous peptide elicitor in Arabidopsis, is functional in transgenic tobacco cells. Proc. Natl. Acad. Sci. USA 103, 10104-10109 (2006).

38. Nandi, A., Welti, R. \& Shah, J. The Arabidopsis thaliana dihydroxyacetone phosphate reductase gene SUPPRESSOR OF FATTY ACID DESATURASE DEFICIENCY1 is required for glycerolipid metabolism and for the activation of systemic acquired resistance. Plant Cell 16, 465-477 (2004).

39. Ross, A. et al. The Arabidopsis PEPR pathway couples local and systemic plant immunity. EMBO J. 33, 62-75 (2014).

40. Ding, Y. et al. Opposite roles of salicylic acid receptors NPR1 and NPR3/ NPR4 in transcriptional regulation of plant immunity. Cell 173, 1454-1467 (2018).

41. Mishina, T. E. \& Zeier, J. Pathogen-associated molecular pattern recognition rather than development of tissue necrosis contributes to bacterial induction of systemic acquired resistance in Arabidopsis. Plant J. 50, 500-513 (2007).

42. Gomez-Gomez, L. \& Boller, T. FLS2: an LRR receptor-like kinase involved in the perception of the bacterial elicitor flagellin in Arabidopsis. Mol. Cell 5, 1003-1011 (2000).

43. Chinchilla, D. et al. A flagellin-induced complex of the receptor FLS2 and BAK1 initiates plant defence. Nature 448, 497-500 (2007).

44. Heese, A. et al. The receptor-like kinase SERK3/BAK1 is a central regulator of innate immunity in plants. Proc. Natl. Acad. Sci. USA 104, 12217-12222 (2007).

45. Lu, D. et al. A receptor-like cytoplasmic kinase, BIK1, associates with a flagellin receptor complex to initiate plant innate immunity. Proc. Natl. Acad. Sci. USA 107, 496-501 (2010).

46. Schulze, B. et al. Rapid heteromerization and phosphorylation of ligandactivated plant transmembrane receptors and their associated kinase BAK1. J. Biol. Chem. 285, 9444-9451 (2010).

47. Roux, M. et al. The Arabidopsis leucine-rich repeat receptor-like kinases BAK1/SERK3 and BKK1/SERK4 are required for innate immunity to hemibiotrophic and biotrophic pathogens. Plant Cell 23, 2440-2455 (2011).

48. Zhang, J. et al. Receptor-like cytoplasmic kinases integrate signaling from multiple plant immune receptors and are targeted by a Pseudomonas syringae effector. Cell Host Microbe 7, 290-301 (2010).
49. Schwessinger, B. et al. Phosphorylation-dependent differential regulation of plant growth, cell death, and innate immunity by the regulatory receptor-like kinase BAK1. PLoS Genet. 7, e1002046 (2011).

50. He, K. et al. BAK1 and BKK1 regulate brassinosteroid-dependent growth and brassinosteroid-independent cell-death pathways. Curr. Biol. 17, 1109-1115 (2007).

51. Zipfel, C. et al. Perception of the bacterial PAMP EF-Tu by the receptor EFR restricts Agrobacterium-mediated transformation. Cell 125, 749-760 (2006).

52. Nekrasov, V. et al. Control of the pattern-recognition receptor EFR by an ER protein complex in plant immunity. EMBO J. 28, 3428-3438 (2009).

53. Cutler, S. R., Ehrhardt, D. W., Griffitts, J. S. \& Somerville, C. R. Random GFP:: cDNA fusions enable visualization of subcellular structures in cells of Arabidopsis at a high frequency. Proc. Natl. Acad. Sci. USA 97, 3718-3723 (2000).

54. Nam, K. H. \& Li, J. BRI1/BAK1, a receptor kinase pair mediating brassinosteroid signaling. Cell 110, 203-212 (2002).

55. Li, J. et al. BAK1, an Arabidopsis LRR receptor-like protein kinase, interacts with BRI1 and modulates brassinosteroid signaling. Cell 110, 213-222 (2002).

56. Ntoukakis, V., Schwessinger, B., Segonzac, C. \& Zipfel, C. Cautionary notes on the use of C-terminal BAK1 fusion proteins for functional studies. Plant Cell 23, 3871-3878 (2011).

57. Singh, A., Lim, G. H. \& Kachroo, P. Transport of chemical signals in systemic acquired resistance. J. Integr. Plant Biol. 59, 336-344 (2017).

58. Rocher, F., Chollet, J. F., Jousse, C. \& Bonnemain, J. L. Salicylic acid, an ambimobile molecule exhibiting a high ability to accumulate in the phloem. Plant Physiol. 141, 1684-1693 (2006).

59. Moore, I., Samalova, M. \& Kurup, S. Transactivated and chemically inducible gene expression in plants. Plant J. 45, 651-683 (2006)

60. Cwiklik, L. \& Jungwirth, P. Massive oxidation of phospholipid membranes leads to pore creation and bilayer disintegration. Chem. Phys. Lett. 486, 99-103 (2010).

61. Tero, R. et al. Nanopore formation process in artificial cell membrane induced by plasma-generated reactive oxygen species. Arch. Biochem. Biophys. 605, 26-33 (2016)

62. Tang, D., Kang, R., Coyne, C. B., Zeh, H. J. \& Lotze, M. T. PAMPs and DAMPs: signal 0s that spur autophagy and immunity. Immunol. Rev. 249 , 158-175 (2012).

63. Vaid, N., Pandey, P. K. \& Tuteja, N. Genome-wide analysis of lectin receptorlike kinase family from Arabidopsis and rice. Plant Mol. Biol. 80, 365-388 (2012).

64. Xin, Z., Wang, A., Yang, G., Gao, P. \& Zheng, Z. L. The Arabidopsis A4 subfamily of lectin receptor kinases negatively regulates abscisic acid response in seed germination. Plant Physiol. 149, 434-444 (2009).

65. Singh, P., Chien, C. C., Mishra, S., Tsai, C. H. \& Zimmerli, L. The Arabidopsis LECTIN RECEPTOR KINASE-VI.2 is a functional protein kinase and is dispensable for basal resistance to Botrytis cinerea. Plant Signal. Behav. 8, e22611 (2013)

66. Yasuda, S., Okada, K. \& Saijo, Y. A look at plant immunity through the window of the multitasking coreceptor BAK1. Curr. Opin. Plant Biol. 38, 10-18 (2017)

67. Yeh, Y. H. et al. The Arabidopsis malectin-like/LRR-RLK IOS1 is critical for BAK1-dependent and BAK1-independent pattern-triggered immunity. Plant Cell 28, 1701-1721 (2016).

68. Stegmann, M. et al. The receptor kinase FER is a RALF-regulated scaffold controlling plant immune signaling. Science 355, 287-289 (2017).

69. Haruta, M., Sabat, G., Stecker, K., Minkoff, B. B. \& Sussman, M. R. A peptide hormone and its receptor protein kinase regulate plant cell expansion. Science 343, 408-411 (2014).

70. Huang, P. Y., Yeh, Y. H., Liu, A. C., Cheng, C. P. \& Zimmerli, L. The Arabidopsis LecRK-VI.2 associates with the pattern-recognition receptor FLS2 and primes Nicotiana benthamiana pattern-triggered immunity. Plant J. 79, 243-255 (2014)

71. Lee, H. J. et al. Systemic immunity requires SnRK2.8-mediated nuclear import of NPR1 in Arabidopsis. Plant Cell 27, 3425-3438 (2015).

72. Gautier, L., Cope, L., Bolstad, B. M. \& Irizarry, R. A. Affy-analysis of Affymetrix GeneChip data at the probe level. Bioinformatics 20, 307-315 (2004).

73. Ritchie, M. E. et al. limma powers differential expression analyses for RNAsequencing and microarray studies. Nucleic Acids Res. 43, e47 (2015).

74. Benjamini, Y. \& Hochberg, Y. Controlling the false discovery rate: a practical and powerful approach to multiple testing. J. R. Stat. Soc. Ser. B 57, 289-300 (1995).

\section{Acknowledgements}

We thank Dr. Ping He (Texas A\&M University, USA) for bak1-5, bkk1, bak1-5 bkk1, $b i k 1$, and BAK1:BAK1-GFP seeds, Dr. Sheng Yang He (Michigan State University, USA) 
for $f l s 2$ efr seeds, Dr. Jean Greenberg (University of Chicago, USA) for ald 1 and azi1 seeds, Dr. Yusuke Saijo (Nara Institute of Science and Technology, Japan) for peprl pepr2 seeds, Dr. Jyoti Shah (University of North Texas, USA) for sfd1 seeds, and Dr. Cyril Zipfel for protocols for measuring ROS burst from leaf disks. This work was partially supported by a Research Opportunity Seed Fund grant from the University of Florida Office of Research awarded to Z.M. and a grant from the National Science Foundation (ISO-1758932) awarded to Z.M.

\section{Author contributions}

C. Wang and Q. Li performed the gene expression, resistance assessment, protein-protein association, and site-directed mutagenesis experiments. X. Huang and Q. Li carried out the radioactivity experiments. Y.Z. conducted the microarray experiment. J.-L.L. analyzed the microarray data. Z.M. secured funding, conceived the research, and wrote the manuscript.

\section{Competing interests}

The authors declare no competing interests.

\section{Additional information}

Supplementary information is available for this paper at https://doi.org/10.1038/s41467019-12781-7.

Correspondence and requests for materials should be addressed to Z.M.
Peer review information Nature Communications thanks Robin Cameron, Stephen Chivasa, Jean Greenberg and the other, anonymous, reviewer(s) for their contribution to the peer review of this work.

Reprints and permission information is available at http://www.nature.com/reprints

Publisher's note Springer Nature remains neutral with regard to jurisdictional claims in published maps and institutional affiliations.

(c) Open Access This article is licensed under a Creative Commons Attribution 4.0 International License, which permits use, sharing, adaptation, distribution and reproduction in any medium or format, as long as you give appropriate credit to the original author(s) and the source, provide a link to the Creative Commons license, and indicate if changes were made. The images or other third party material in this article are included in the article's Creative Commons license, unless indicated otherwise in a credit line to the material. If material is not included in the article's Creative Commons license and your intended use is not permitted by statutory regulation or exceeds the permitted use, you will need to obtain permission directly from the copyright holder. To view a copy of this license, visit http://creativecommons.org/ licenses/by/4.0/.

(C) The Author(s) 2019 